\title{
Thyroid nodule ultrasound: technical advances and future horizons
}

\author{
Andrew S. McQueen • Kunwar S. S. Bhatia
}

Received: 17 December 2014 / Revised: 28 January 2015 / Accepted: 4 February 2015 / Published online: 5 March 2015

(C) The Author(s) 2015. This article is published with open access at Springerlink.com

\begin{abstract}
Thyroid nodules are extremely common and the vast majority are non-malignant; therefore the accurate discrimination of a benign lesion from malignancy is challenging. Ultrasound (US) characterisation has become the key component of many thyroid nodule guidelines and is primarily based on the detection of key features by high-resolution US. The thyroid imager should be familiar with the strengths and limitations of this modality and understand the technical factors that create and alter the imaging characteristics. Specific advances in highresolution US are discussed with reference to individual features of thyroid cancer and benign disease. Potential roles for three-dimensional thyroid ultrasound and computer-aided diagnosis are also considered. The second section provides an overview of current evidence regarding thyroid ultrasound elastography (USE). USE is a novel imaging technique that quantifies tissue elasticity (stiffness) non-invasively and has potential utility because cancers cause tissue stiffening. In recent years, there has been much research into the value of thyroid USE for distinguishing benign and malignant nodules. Preliminary findings from multiple pilot studies and metaanalyses are promising and suggest that USE can augment the anatomical detail provided by high-resolution US. However, a definite role remains controversial and is discussed.
\end{abstract}

Andrew S. McQueen and Kunwar S.S. Bhatia contributed equally to this work.

A. S. McQueen

Freeman Hospital, Newcastle upon Tyne, UK

K. S. S. Bhatia $(\bowtie)$

Department of Imaging \& Interventional Radiology, The Chinese

University of Hong Kong, Prince of Wales Hospital, Shatin,

N.T., Hong Kong

e-mail: drkbhatia@cuhk.edu.hk
Teaching points

- High-resolution US characterises thyroid nodules by demonstration of specific anatomical features

- Technical advances heavily influence the key US features of thyroid nodules

- Most papillary carcinomas appear stiffer than benign thyroid nodules on US elastography (USE)

- Thyroid USE is controversial because of variation in the reported accuracies for malignancy

- Combined grey-scale US/USE may lower the FNAC rate in benign nodules

Keywords Thyroid nodules · Thyroid cancer · Ultrasound · Elastography $\cdot$ Malignancy

\section{Introduction}

Ultrasound (US) examination of the neck is a commonly performed investigation and thyroid nodules are a highly prevalent finding. As the vast majority of nodules are non-malignant, the accurate discrimination of a benign from cancerous lesion is an important and challenging feature of thyroid US. Whilst single US features remain of limited accuracy, constellations of findings enable thyroid nodules to be accurately stratified on a 'risk-of-malignancy' basis and form the basis of several guidelines $[1,2]$. Imaging features that confer a high positive predictive value and specificity for malignancy are valuable as they enable suspicious lesions to be identified and targeted for pathological analysis (typically fine-needle aspiration cytology, FNAC). The ubiquitous nature of thyroid nodules and the limitations of cytology mean that the confident identification of benign nodules is also important. US characteristics that carry a high negative predictive value for malignancy enable an evidence-based decision not to investigate further, allowing unnecessary FNAC and/or surgery to be 
avoided in a very large population. Many of these key thyroid nodule features are heavily dependent on recent advances in high-resolution ultrasound technology and are therefore altered and influenced by US machine settings. In an era of wider US use by different groups (e.g., endocrinologists, surgeons), the high-resolution features of thyroid disease - and the technical factors, which create and alter these valuable signs - must be familiar to the operator.

US elastography (USE) is a recent technological advance that measures tissue elasticity or stiffness properties objectively and has been available in recent years on many state-of-the-art clinical US machines. USE is classified as diagnostic ultrasound and is safe, non-invasive and requires no costly consumables. Importantly, USE can be performed in real-time alongside conventional sonography, providing objective stiffness data that can be used to influence clinical decisions during US examinations. The clinical potential of USE relies on the same principles as clinical palpation, namely that processes such as malignancy and fibrosis alter elasticity. Numerous clinical applications of USE are under investigation at different body sites. To date, over 100 preliminary studies on USE for thyroid nodules for malignancy have been published, with promising but controversial results, as will be discussed.

This article will focus on two aspects of thyroid ultrasound: first, technical advances in high-resolution US are discussed with relevance to specific features of thyroid cancer, benign disease and emerging developments. The second part of the article provides a concise overview of the current role of elastography and how elasticity imaging may supplement high-resolution ultrasound in the pursuit of accurate thyroid nodule assessment.

\section{Advances in ultrasound image resolution}

Thyroid nodule detection, margin delineation and size measurement are heavily influenced by spatial resolution. Modern high-frequency US probes utilise piezoelectric material that resonate at higher frequencies and across wider bandwidths (i.e., PureWave ${ }^{\mathrm{TM}}$, Philips) than older crystals. Improving the source piezoelectric material enables the effective bandwidth of the probe to be used more efficiently and uniformly than was previously possible [3]. The resulting improvements in spatial resolution are particularly beneficial in superficial structures such as the thyroid. In addition, probes now contain higher numbers of elements (e.g., high-density 18 L6, Siemens ACUSON) facilitating more versatile beam forming and providing the basis for increasingly advanced compound imaging. Spatial compounding refers to composite images created by insonations from transmitted pulses at multiple different angles to the probe surface (Fig. 1) whilst frequency compounding generates images based on a range of frequencies across the probe bandwidth [4]. The two techniques are often used simultaneously, producing higher resolution images with smooth tissue planes and increased signal-to-noise ratios. Traditionally, these methods of improving spatial resolution have come at a cost: a reduced frame rate (temporal resolution) due to the conventional ultrasound transmitreceive cycle. The newest technical developments aim to minimise this limitation; an example is the use of precision beamforming, multi-line transmission and parallel processing (nSIGHT $^{\mathrm{TM}}$, Philips) to combine high spatial and temporal resolution. As a final consideration, the availability of highdefinition, multi-position monitors enables the information acquired and processed by the transducer to be clearly displayed for interpretation.

Contrast resolution settings are the primary factors that influence the assessment of nodule consistency, reflectivity and the detection of echogenic foci due to calcium or colloid. Whilst broader bandwidths allow improved beam penetration in the neck, the majority of advances in this aspect of thyroid ultrasound relate to how the echoes are received and processed rather than the pulse transmission. Signal processing (also known as speckle reduction) techniques are designed to interrogate lines of echoes obtained on each frame and improve the signal-to-noise ratio by pattern recognition [5]. For example, an anechoic area containing background noise will be recognised as a cystic structure and the abrupt change in echoes around the margins of this target then recognised as the cyst/vessel wall (e.g., Precision Imaging ${ }^{\mathrm{TM}}$, Toshiba). This process of removing unwanted noise leads to images that look sharper because of the improved signal-to-noise ratio and emphasise cystic vs. solid consistency. The dynamic range and grey-scale map are inherently linked but different aspects of high-resolution ultrasound. The dynamic range controls the range of grey (or the preferred colour tint) that is available to display echo intensity, whilst the grey-scale map allocates which parts of this spectrum are used to represent the echo signals received [6]. Tissue harmonic imaging (THI) - an established technique for improving image contrast at other body sites - has recently become more relevant to highfrequency ultrasound. As the basis of this technique is to receive a signal from the second harmonic frequency of the probe's transmit pulse (i.e., twice the probe transmit frequency), its use in superficial structures has been limited [7]. However, the advent of wider bandwidths and more sophisticated receive technology means that THI is increasingly available to use with high-frequency probes (e.g., Hitachi High definition dynamic THI) resulting in further removal of clutter/noise and improved tissue contrast. Basic ultrasound settings (focal zones, time gain control, etc.) also affect image quality but are not covered in this article.

The following key thyroid nodule characteristics are heavily influenced by these improvements in image resolution. 
Fig. 1 High-resolution images through a phantom using perpendicular (a) and spatial compounding (b) beams. Courtesy of Toshiba

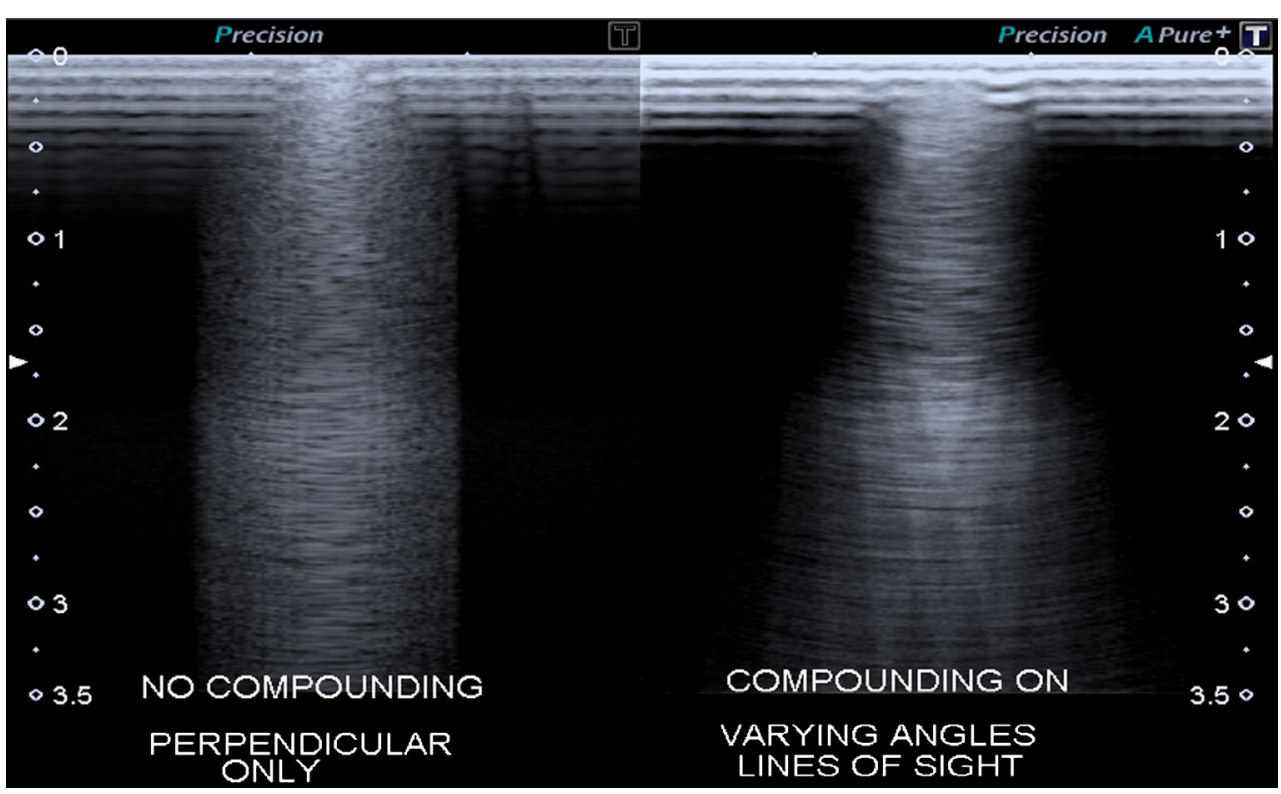

Whilst multiple factors contribute to the assessment of these signs, the predominant technical consideration is discussed for each in turn:

\section{- Margin delineation:}

An abnormal thyroid nodule margin is a recognised feature of thyroid malignancy. Assessment of the nodule edge has previously been binary; the margin is either well or poorly defined. A poorly defined/irregular nodule margin conferred $87 \%$ specificity for malignancy in a study population of 1,108 thyroid nodules but with a very low sensitivity of $39 \%$ [8]. Whilst operator experience is an important factor in edge delineation, the machine settings heavily influence this assessment and create a challenge for standardised reporting between observers using different equipment. The probe frequency, bandwidth and use of compound imaging are the key technical aspects to consider here (Fig. 2), delivering improved signal-to-noise ratios for the operator to delineate the nodule from the surrounding thyroid parenchyma and adjacent structures. More recently, the concept of a 'spiculated' margin (Fig. 3) has been introduced to describe the finding of a distinctly infiltrative nodule edge (as separate from the broader 'poorly defined' category) with $92 \%$ specificity and $81 \%$ positive predictive value in a comprehensive review of B mode ultrasound findings [9]. The ability to detect margin spiculation is a consequence of higher spatial and temporal resolution and it therefore follows that the reliable detection of this useful characteristic requires access to the advances in the above-described ultrasound technology. Understanding the close relationship of technology to sonographic interpretation is particularly important because — of all the individual thyroid nodule features - margin delineation has the poorest inter-observer agreement [10]. The multiple technical factors are likely to contribute to this variability and are particularly relevant when patients undergo thyroid ultrasound at different centres with varying ultrasound probe and software settings.

\section{- Smaller nodule detection:}

The rising incidence of thyroid cancer across many countries is almost entirely attributable to small $(<2 \mathrm{~cm})$ papillary carcinoma [11]. Multiple factors have contributed to the phenomenon of the clinically occult papillary thyroid cancer; incidental detection on other imaging modalities, patient awareness and access to health care amongst others. The ability to visualise and identify suspicious features within these small nodules (e.g., margin irregularity, microcalcification) is, however, a consequence of the advances in high-resolution ultrasound. Sub-centimetre nodules can be identified, characterised and targeted for FNA if appropriate (Fig. 4). This has created difficulty for guidelines that have been primarily based on nodule size (i.e., the Society of Radiologists in Ultrasound [12]), particularly given the increasing understanding that size alone is not an accurate predictor of malignancy [13]. Moreover, improved resolution enables better needle tip visualisation during US-guided FNA/biopsy and obtaining an adequate cytological specimen from very small (i.e., $5 \mathrm{~mm}$ ) nodules is feasible, although lower adequacy rates are reported from FNA of these smallest lesions [13]. The clinical benefit of confirming malignancy in this setting is controversial - and beyond the scope of this article - as the prognosis for small papillary thyroid cancers is generally excellent, prompting the proposal of a separate nomenclature, 'papillary lesion of indolent course' [11]. The reality for the thyroid US operator at present is that he or she will regularly 
Fig. 2 Transverse images of a predominantly cystic left lobe nodule obtained without (left) and with (right) spatial and frequency compounding software. Note the improved delineation of the thyroid (arrow) and cystic nodule (block arrow) margins

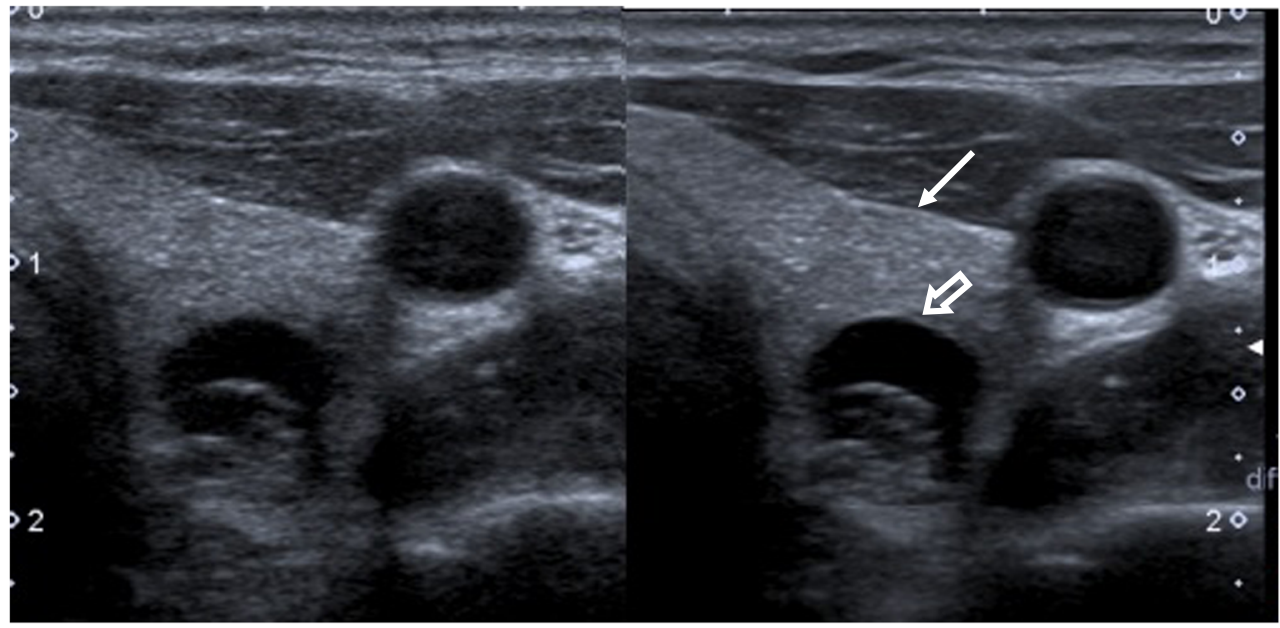

be confronted with small but suspicious incidental nodules that would previously have remained undetected.

\section{- Nodule consistency}

The majority of malignant nodules are solid, but the majority of solid nodules are benign. Whilst solid nodule consistency is of very limited value in identifying thyroid cancer, the finding of microcystic aggregates creating a 'spongiform' appearance is an extremely strong predictor of benignity ( $99.7 \%$ negative predictive value) [9]. As purely cystic nodules are also confidently benign, the ability to accurately detect cystic spaces within a nodule is an important facet of the ultrasound assessment. Spongiform areas can be detected with the aid of compound imaging whilst speckle reduction software

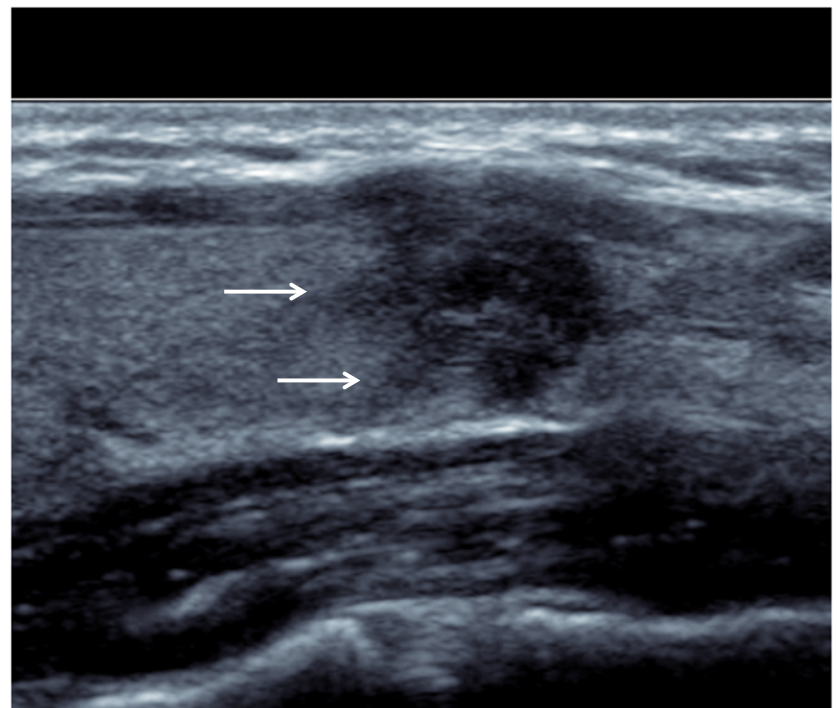

Fig. 3 Longitudinal image of a hypoechoic nodule with a spiculated margin (arrows) and anterior capsular breach on high-resolution ultrasound. The lesion was confirmed as a papillary thyroid carcinoma on surgical resection removes the noise/clutter from the small cystic spaces. Without the use of these techniques, speckle artefact and blurred septations can mimic solid components and lead to unnecessary investigation of benign nodules.

\section{- Nodule reflectivity}

Most thyroid cancers are hypoechoic compared to the background parenchyma. Unfortunately, this finding is nonspecific as benign nodules can also be hyporeflective and the comparison with 'normal' thyroid may be hampered by background nodularity or thyroiditis. By comparison, marked hypoechogenicity - defined as 'less reflective than adjacent strap muscle'-is a specific malignant finding with an odds ratio of 8.46 in a retrospective study of 849 thyroid nodules [14]. Although this feature is only seen in the minority of cancers, its recognition makes a benign nodule unlikely and will typically initiate further investigation with FNAC (Fig. 5). Dynamic range and grey-scale map settings predominantly control image contrast whilst the use of harmonic imaging will further emphasise differences in reflectivity. A narrow dynamic range will increase the contrast between adjacent structures by utilising fewer shades of grey to display the echo signal intensity. Whilst these settings are typically configured within manufacturer presets, they can be altered easily on most ultrasound platforms and should ideally be customised to the user's preferences. The clinical value of marked hypoechogenicity as a specific sign of thyroid cancer emphasises the importance of being familiar with one's own machine settings.

\section{- Echogenic foci-colloid vs. calcium}

In addition to the choice of the dynamic range and greyscale map, signal processing techniques help to identify small hyperechoic foci. Bright spots that show a 'ring down' or 'comet tail' artefact are a very helpful finding; they represent 
Fig. 4 Longitudinal image of a 1.5-cm nodule (block arrow) detected incidentally on cervical spine MRI. This nodule is spongiform and appears confidently benign. However, a 0.6-cm ill-defined nodule alongside (arrow) is hypoechoic and contains microcalcificationFNA was performed from this nodule and confirmed papillary thyroid carcinoma

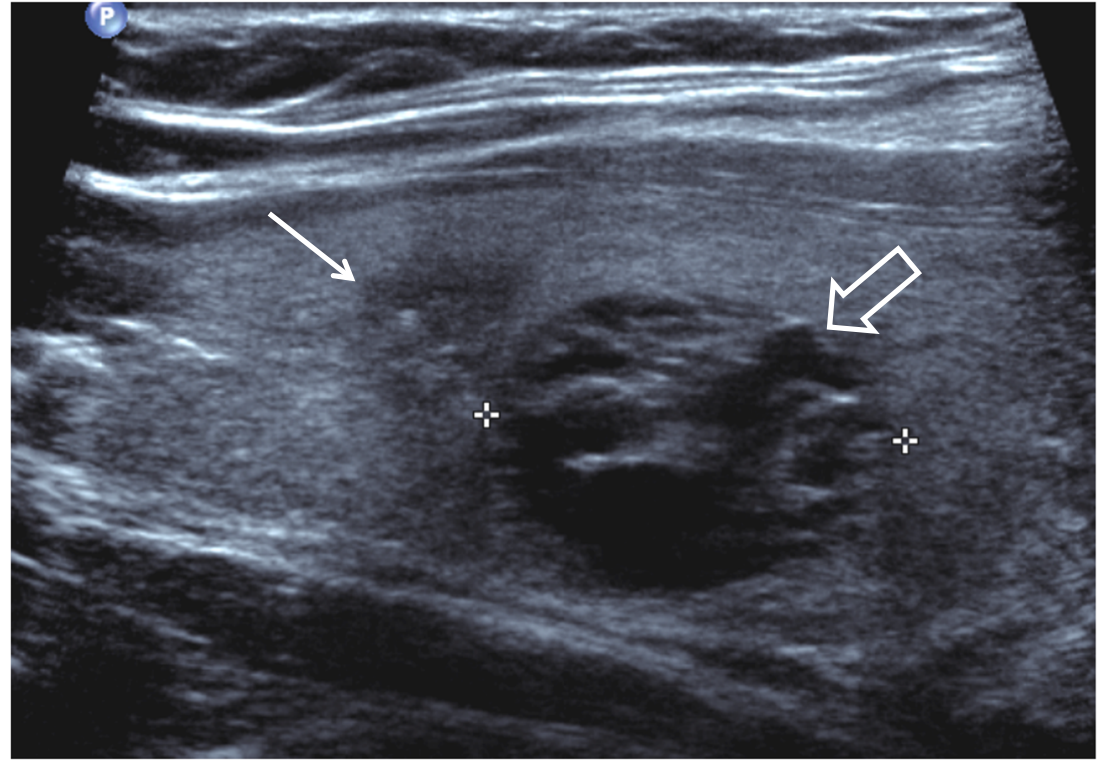

foci of inspissated colloid and are a feature of benign nodules. Conversely, the presence of sub-millimetre, highly reflective foci with or without acoustic shadowing represents microcalcification - a specific feature of differentiated thyroid malignancy [15]. The depiction of the comet tail artefact is therefore crucially important to confirm the benign nature of an echogenic focus. As would be expected, signal processing emphasises the bright focus and can help to make the comet tail more conspicuous to the operator (Fig. 6).

Traditionally, the detection of microcalcification (usually due to small psammoma bodies within papillary thyroid

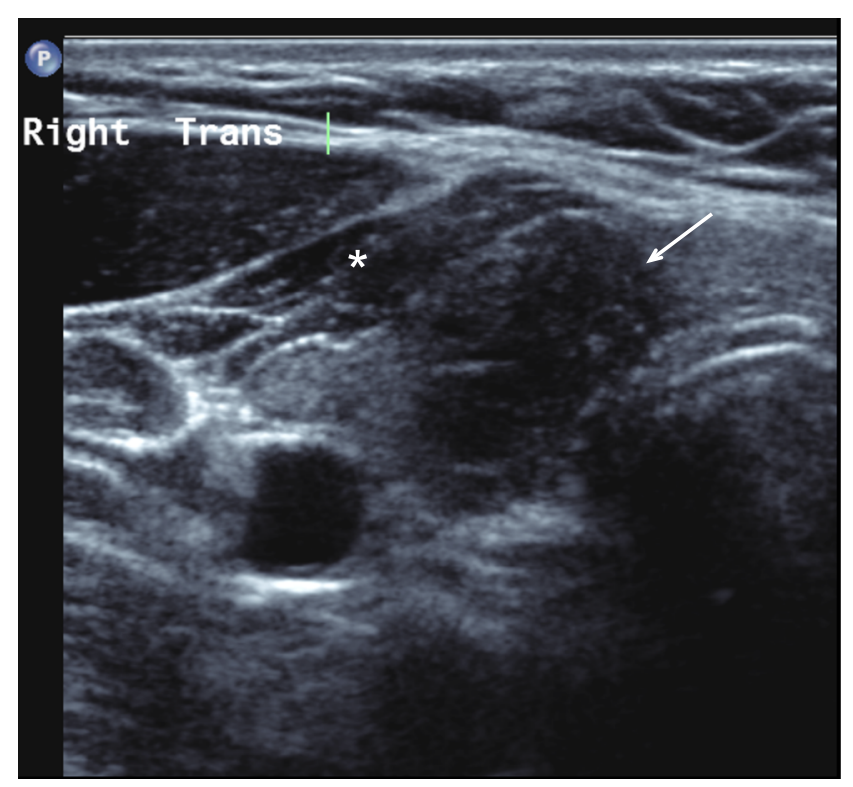

Fig. 5 Transverse image of the right thyroid lobe showing a nodule (arrow) of slightly lower reflectivity than the adjacent strap muscle $\left(^{*}\right)$, i.e., 'markedly hypoechoic'. A pT1b infiltrative, classical papillary thyroid carcinoma was found on surgical resection cancer) was made easier by the associated acoustic shadow artefact created by reflection of the perpendicular ultrasound beam [16]. In high-resolution ultrasound, the use of spatial compounding means that the signal can be received from tissue deep to calcific foci (Fig. 7) and this artefact is often diminished or lost in the thyroid. This unwanted consequence of modern technology can be overridden by deactivating spatial compounding and allowing acoustic shadows to emergeif the operator understands the significance of the artefact and its causation.

An alternative method of highlighting microcalcification within thyroid nodules is to alter the grey-scale map, dynamic range and speckle reduction combination (Fig. 8). Boosting the brightness of the signal received from calcific spots relative to normal parenchyma increases the detection and has been investigated in breast ultrasound (where the identification of microcalcification also carries significant clinical value) [17]. A novel modified grey-scale map/image tint combination to detect microcalcification (MicroPure Imaging, Toshiba) has been recently reported in thyroid nodules [18].

\section{Emerging uses of thyroid ultrasound}

The technological progress of B mode US enables the thyroid gland to be assessed in more anatomic detail than ever before, characterising lesions by a matrix of structural features. Building on these advances, the value of three-dimensional US in thyroid nodule assessment has recently been considered [19-21]. Initial studies have focussed on two aspects: the ability to more accurately assess the key B mode features (e.g., nodule margin) and the potential to uncover independent predictors of malignancy from 3D data sets. Whilst 3D US is not widely used in the neck at present, recent developments in this 
Fig. 6 A cystic nodule without (left) and with (right) signal processing software active. Note the increased conspicuity of the comet tail artefact (arrow) on the active image. Images courtesy of Dr S.T. Elliott

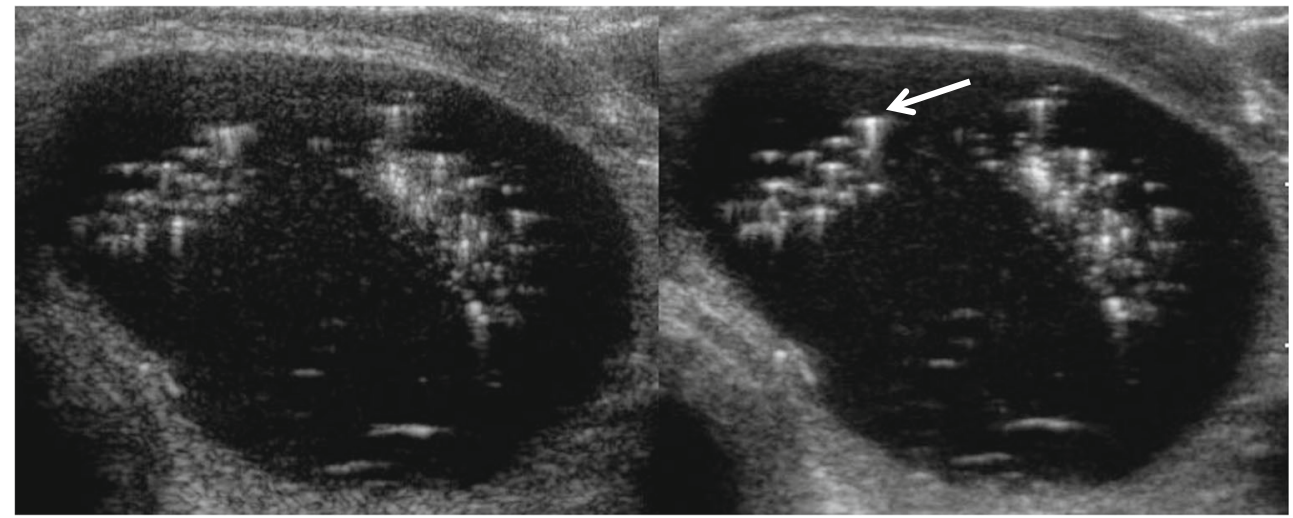

area suggest the potential to address persisting challenges of thyroid imaging.

In a prospective study of 91 thyroid nodules, the interobserver agreement for specific characteristics (e.g., shape, margin) was better for 3D than 2D US. Although intra-observer agreement remained suboptimal, there was significantly stronger agreement between users for suspicion of malignancy after off-line review of the static 3D images [21]. National guidelines are increasingly based on standardised classification of malignant risk [1,22] (as opposed to subjective assessment by experienced individuals); therefore reducing inter-observer variation is particularly relevant $[1,21,22]$.

In a retrospective study of 71 thyroid nodules, 3D ultrasound data were analysed using multiplanar reformatted (MPR) images and a thin-slice volume-rendered technique [19]. The MPR data found that poorly defined 3D nodule margins were associated with malignancy but also described two novel, independent 3D predictors of malignancy: a lobulated nodule shape in the C-plane (coronal) and altered central $3 \mathrm{D}$ vascularity. The smooth surface, thin-slice volumerendering algorithm created images with higher contrast and reduced noise: a new layer of post processing to compare with existing 2D techniques. The shift in emphasis from real-time image interpretation to volume acquisition with subsequent processing and multiplanar viewing also offers potentially more detailed data analysis. A study of 20 thyroid nodules assessed 3D high-resolution ultrasound data with a computer-aided diagnostics (CAD) software programme [20]. The authors found that CAD-detected specific 3D textural features could be identified and combined as an accurate discriminator of benign and malignant nodules, creating automated malignant risk stratification ('Thyroid Malignancy Index'). Such an approach would represent a paradigm shift in practice for most thyroid imagers but the potential for accurate objective data to support an operator's skill and experience is attractive.
Fig. 7 Longitudinal images of carotid bulb atheroma without (left) and with (right) spatial compounding active. Note the diminished acoustic shadow with spatial compounding (arrows) despite the overlying coarse calcification. Images courtesy of Dr S.T. Elliott

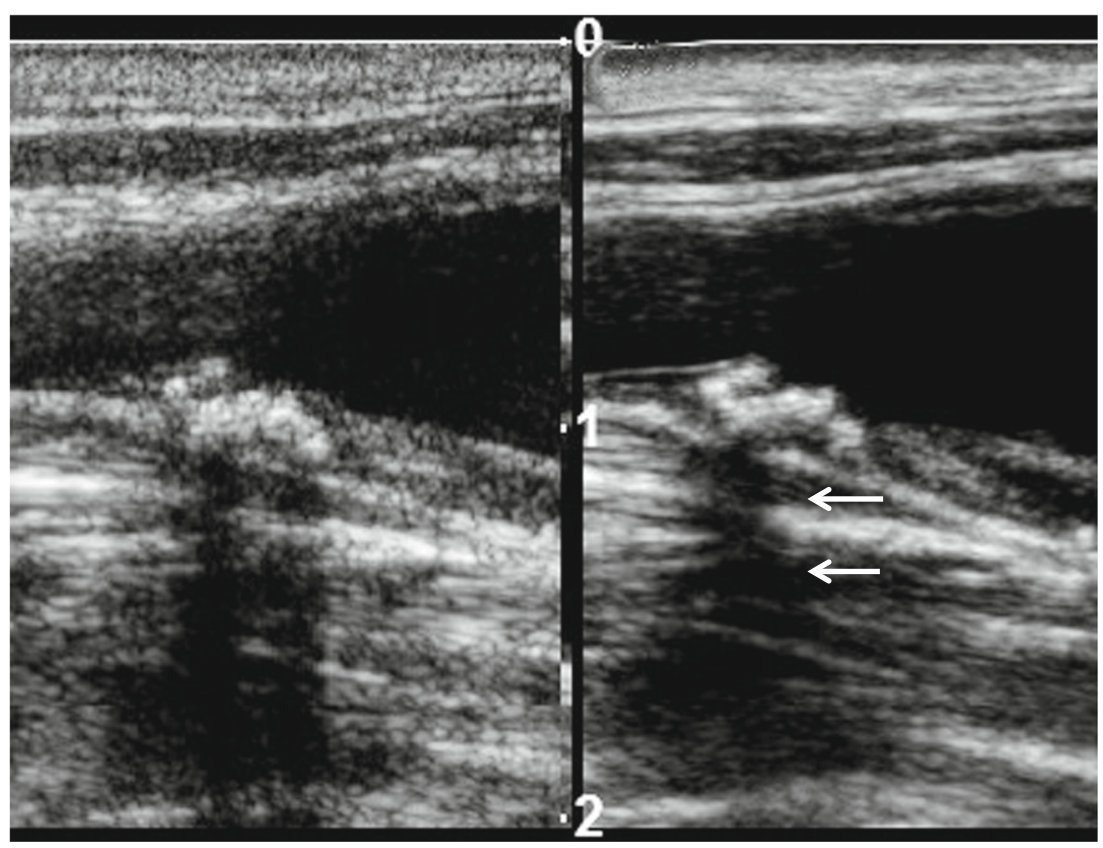




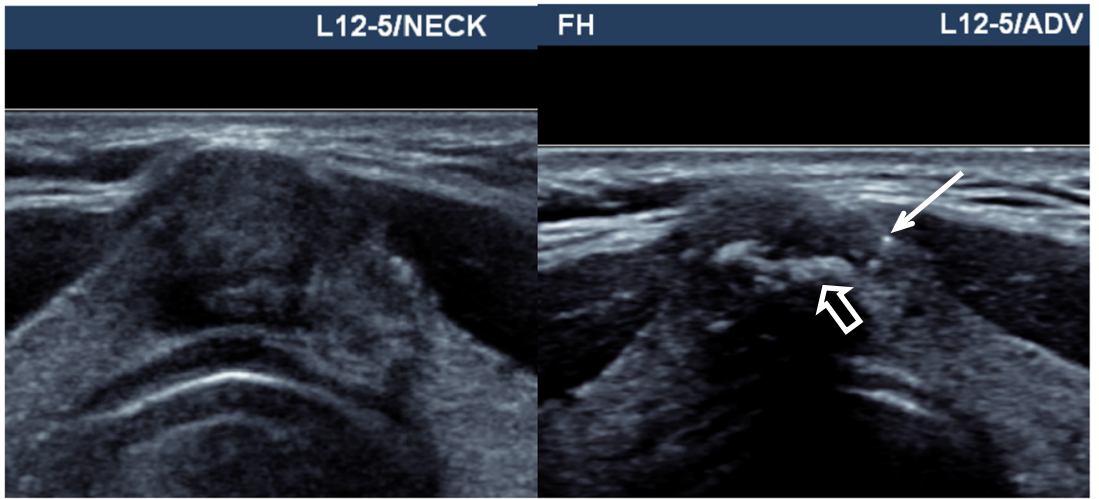

Fig. 8 Transverse images of a $1-\mathrm{cm}$ thyroid isthmus nodule using standard thyroid ultrasound (left) and modified grey-scale map/dynamic range presets (right). Macro- (block arrow) and microcalcifications (arrow) are much more conspicuous with the modified preset, originally

Regarding contrast-enhanced ultrasound (CEUS), a small number of studies have documented the feasibility and diagnostic accuracy of assessing thyroid nodule enhancement following intravenous microbubble contrast, using low mechanical index (MI) settings [23, 24]. Recognisable quantitative patterns of perfusion have been identified to construct CEUS malignant risk stratification with $76.9 \%$ sensitivity and $84.8 \%$ specificity in a study of 42 patients [24]. These findings suggest a potential role for CEUS as a diagnostic adjunct to B mode US but the technique is more invasive and timeconsuming than standard ultrasound and, at present, the specific clinical utility is unclear.

\section{US elastography (USE)}

\section{- Basic principles}

Elasticity refers to the tendency of a tissue to undergo a reversible deformation and is quantified by Young's modulus $(E)$ in kiloPascals $(\mathrm{kPa})$, which equals the ratio of an applied stress to the induced strain (displacement/original length) [25, 26]. USE technologies either estimate elasticity or a surrogate parameter such as strain from US signals acquired during a mild tissue deformation, which can be displayed twodimensionally as elastograms. A range of proprietary USE technologies is available commercially, which can be divided into strain elastography (strain USE) and shear wave elastography (SWE) based on their underlying physics.

In strain USE, also known as quasi-static elastography, compression elastography and real-time elastography (RTE), a mechanical stress is used to deform the tissue of interest and returning US signals are software processed to generate dynamic elastograms of relative tissue strain. In the thyroid, either the operator applies freehand compression to gently compress and decompress a nodule axially under the transducer, or designed to detect calcification in breast lesions. A follicular variant papillary thyroid carcinoma containing dystrophic and psammomatoid calcification was confirmed on resection

alternatively nodules in the lateral lobe may be compressed solely by transmitted pulsations from the adjacent common carotid artery (Fig. 9). Elastograms are displayed as an opacity layer over and beside corresponding grey-scale US images (split screen mode) using a chromatic scale that varies between manufacturers. Operators performing freehand compression must use a precise manual technique to generate high-quality elastograms, which can be optimised by referring to compression quality scales that are automatically computed and displayed in real time (Fig. 10). Strain elastograms are either interpreted qualitatively, based on visual grading of the proportion and distribution of different colours within the nodule (Fig. 11), or semi-quantitatively using strain ratios (computed from regions of interest (ROIs) placed in the nodule and adjacent thyroid parenchyma) or other indices such as strain heterogeneity. Presently, there is no agreement on an optimal qualitative scoring system although many investigators have used 4- or 5-point scales whereby higher elastography scores (ES) signify higher nodule stiffness [27, 28]. Strain USE is unsuitable for nodules without sufficient reference tissue in the elastogram, which basically excludes single or conglomerate nodules exceeding $\sim 3 \mathrm{~cm}$ diameter.

SWE technologies applicable to thyroid imaging use highly focused ultrasound impulses to induce minuscule localised lateral displacements at different locations within the tissue called shear waves, followed by ultrasound detection impulses to track shear wave propagations [25]. SWE is also known as acoustic radiation force impulse imaging (ARFI). Shear waves travel faster in stiffer tissues, whereby shear wave velocity (SWV) is directly proportional to the square root of Young's modulus. Unlike strain USE, SWE output is quantitative; expressed as SWV $(\mathrm{m} / \mathrm{s})$ or estimated tissue stiffness $(\mathrm{kPa})$. Due to differences in proprietary SWE technologies between manufacturers, SWE outputs are varied. These include static colour-coded elastograms termed 2D SWE or a single numerical estimate for an ROI of fixed dimensions $(\sim 5 \times 6 \mathrm{~mm})$ 
Fig. 9 Schematic illustration of (a) strain USE and (b) SWE for a hard (red) and soft (green) nodule. In strain USE, tissues are deformed mechanically by the operator via motion of the transducer or by an external source. Relative displacement (strain) is greater in soft compared to stiff tissues. In SWE, focused acoustic impulses from the transducer induce laterally propagating shear waves, whose velocities are higher in stiffer tissues. Tissue displacements in both techniques are tracked by ultrasound detection impulses (not shown)
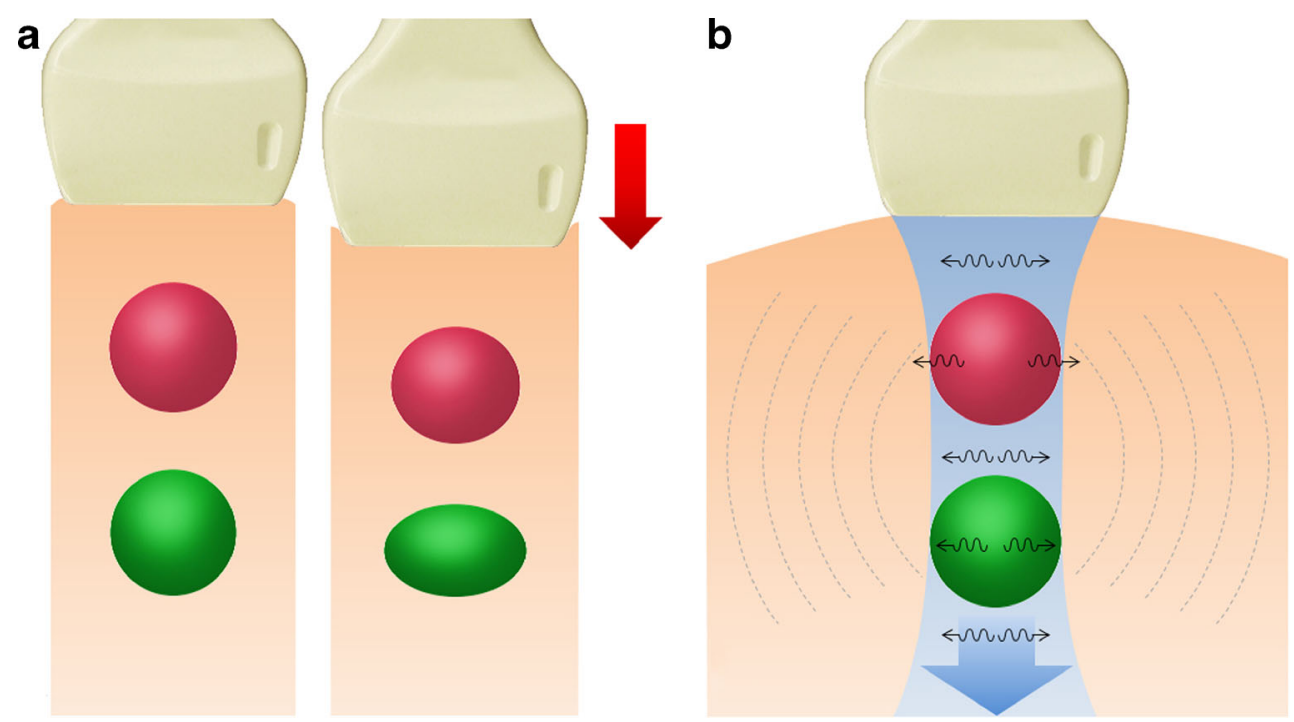

termed point SWE (pSWE). At least one commercial SWE system produces elastograms in real time, from which SWV or Young's modulus estimates can be computed for ROIs selected by the operator (Fig. 12).

\section{- Accuracy of USE for malignancy}

Presently about 80 studies of strain USE and 20 studies of SWE have been published for thyroid malignancy since 2005 [29-35]. Most are single-institutional series with heterogeneous designs, comprising around 100 nodules selected for FNAC or surgery because of suspicious or equivocal sonographic features, suspicious or malignant cytology or nodules within a compressive goitre. Most studies have also variably excluded nodules containing coarse macro-calcifications, substantial cystic areas or those within a diffuse thyroiditis as early evidence suggested that USE is suboptimal in these cases. Due to this selection bias, a much higher proportion of nodules in these studies is malignant $(\sim 25 \%)$ than in an unselected population $(\sim 5 \%)$ and most are papillary carcinomas ( $\sim 90 \%)$; thus published discriminatory performance data actually refer to this histological type [29-35].

Promisingly, most studies indicate that papillary cancers have significantly higher stiffness indices on USE compared to benign nodules although there is some overlap (Figs. 11, 12, 13 and 14). Furthermore, most evidence suggests that USE has a superior overall accuracy compared to single or multiple conventional US criteria. Multiple meta-analyses confirm these findings [29-35] including the largest to date, which reports a pooled mean sensitivity, specificity, PPV, NPV and accuracy of $87,80,47,97$ and $81 \%$ for strain USE using freehand compression $(N=4,926) ; 87,80,52,100$ and $82 \%$ for strain USE using carotid artery pulsation $(N=241)$ and $86,89,60,97$ and $89 \%$ for SWE [34]. From the pooled data, SWE has higher accuracy compared to strain USE, while performing strain USE using carotid arterial pulsations is slightly superior

Fig. 10 Longitudinal strain USE and B mode US of a papillary carcinoma (white arrow). Colour scale in the top left shows stiff, intermediate and soft areas as blue, green and red, respectively. The nodule appears mostly blue suggesting a firm nodule. Compression quality feedback scales are displayed in real time to assist operators in optimising their technique (arrowheads)

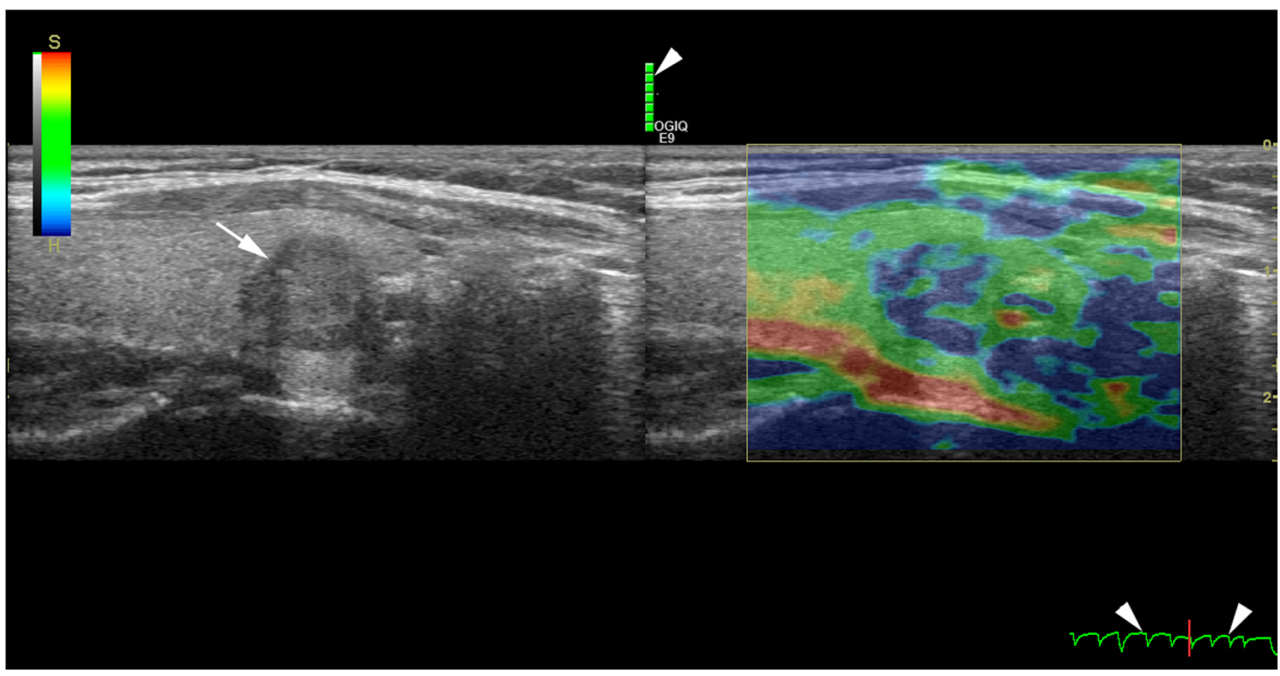


Fig. 11 Strain USE scoring system showing a typical 4-point qualitative scoring system. The chromatic scale in this machine, shown on the right side of each elastogram, differs from that used on the machine used to generate Fig. 10, with red and purple colours denoting high and low relative stiffness respectively. The examples shown for ES1 and ES2 were a collapsed haemorrhagic cystic nodule and benign hyperplastic nodule respectively, and ES3 and ES4 were papillary carcinomas. These examples would be classified correctly using most scoring systems published to date, which generally apply a strain USE threshold of ES3 or greater to predict malignancy

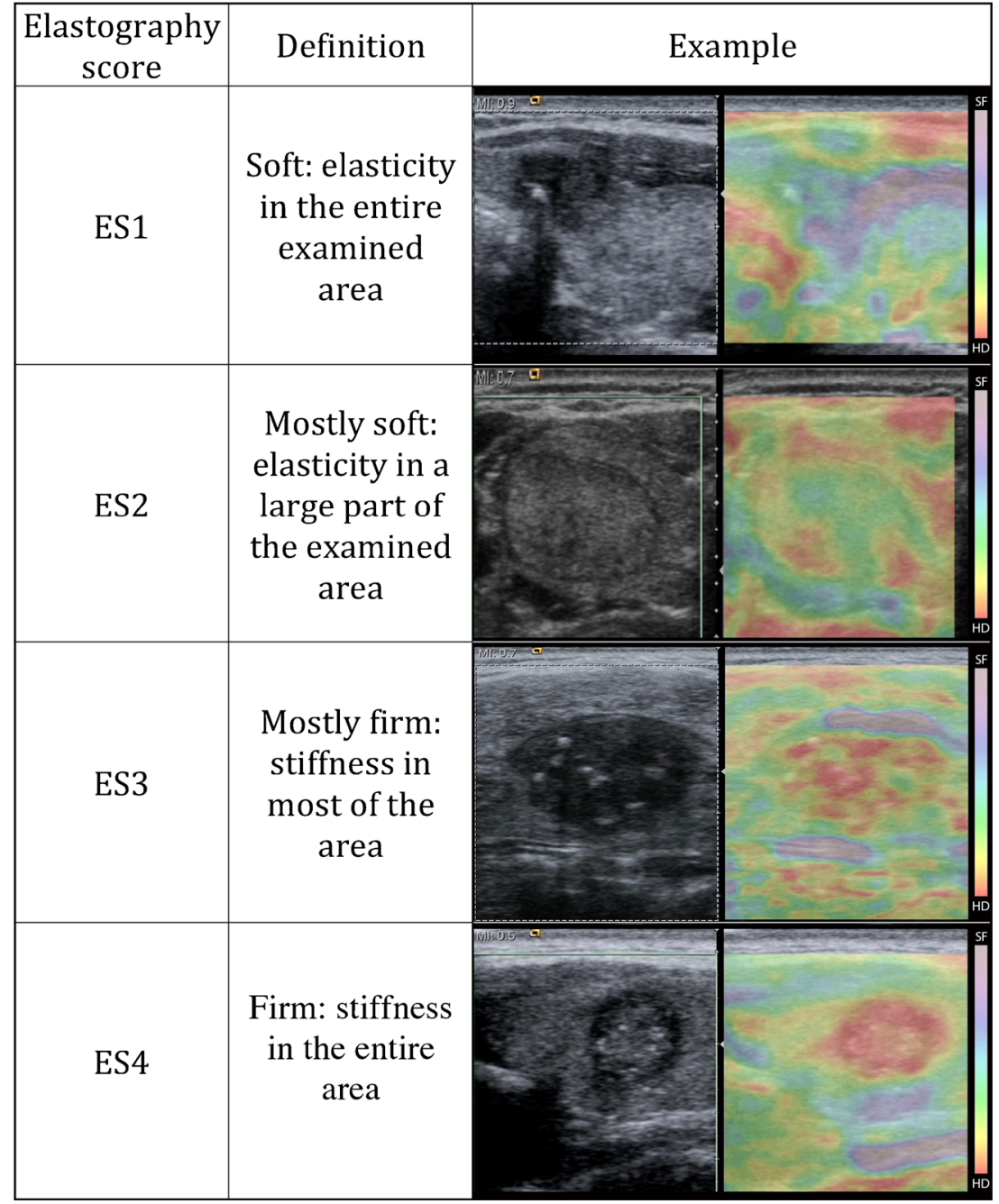

diagnostically compared to freehand compression. The precise cause for the high stiffness of papillary cancers needs to be clarified but probably reflects intense tumour fibrosis, with or without calcifications, which is characteristic of this

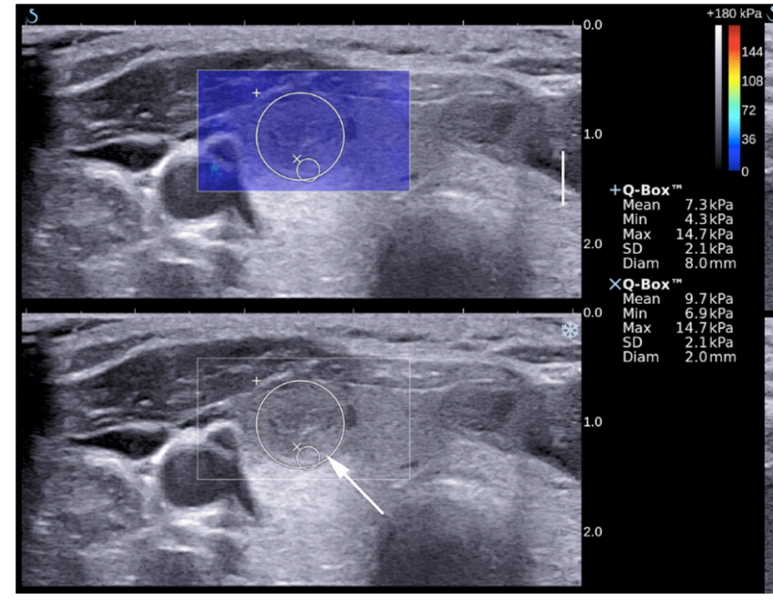

Fig. 12 Transverse and longitudinal SWE with B mode US image of a hyperplastic nodule (left) and of a papillary carcinoma (right) respectively. The SWE elastogram chromatic scale ranges from blue to red, denoting soft to stiff ( $0 \mathrm{kPa}$ to $180 \mathrm{kPa})$. Quantitative measurements

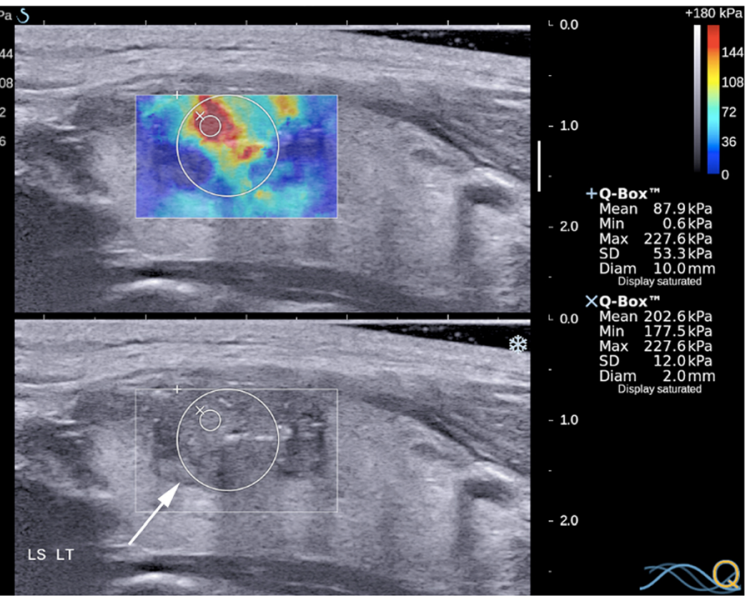

are acquired for operator-placed ROIs. The benign nodule has a maximum SWE stiffness of $14.7 \mathrm{kPa}$ whereas the cancer has a maximum stiffness of $227.6 \mathrm{kPa}$ 


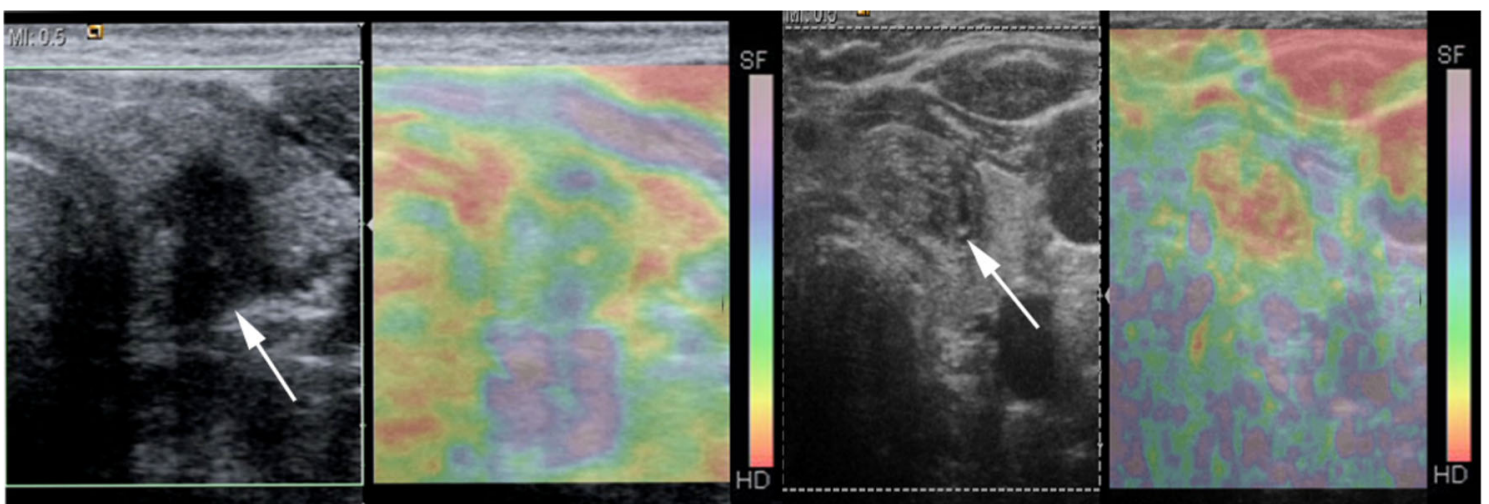

Fig. 13 Transverse strain USE with B mode US images of a papillary carcinoma (left) and hyperplastic nodule (right). Using the qualitative scoring scale from Fig. 11, the cancer appears soft (ES1) whereas the hyperplastic nodule appears mostly stiff (ES3). These would be false

histology although not always present ( $\sim 80 \%)$ [36]. Indeed, anecdotal examples of high USE indices are reported for benign nodules containing dense fibrotic foci and calcifications histologically as well as low USE indices in some papillary and follicular cancers lacking substantial fibrosis [37].

Despite the mostly promising data described above, a role of USE in thyroid nodules is controversial because of a marked heterogeneity in published accuracy results including optimised cutoffs for malignancy, and importantly a small but significant number of recent studies have markedly suboptimal findings [38-43]. One study assessed 703 nodules by conventional US and qualitative strain USE ( $31 \%$ cancer) and reported a suboptimal diagnostic performance for USE (65\% sensitivity, $58 \%$ specificity and $61 \%$ accuracy) in comparison with conventional US ( $92 \%$ sensitivity, $67 \%$ specificity and $74 \%$ accuracy) or combined US/USE [42]. Even among studies of strain elastography using semi-quantitative SRs, there is a wide dispersion in mean SRs of benign and negative and false positive for malignancy using most scoring systems published to date, which apply a strain USE threshold of ES3 or greater to predict malignancy

malignant nodules as well as optimal cutoffs for malignancy [44-49]. Discrepant results have also been documented for quantitative USE. For example, optimised cutoffs for malignancy in studies using an identical SWE technology range between $39.3 \mathrm{kPa}$ and $66 \mathrm{kPa}$, and corresponding diagnostic performances range between $52.9 \%$ sensitivity, $77.8 \%$ specificity to $85.2 \%$ sensitivity, $93.9 \%$ specificity $[50,51]$. The reasons for the wide variation in results are unclear at present.

\section{- Potential role of use in clinical practice}

Approximately a dozen studies have evaluated the combined performance of USE with US (US/USE) [40, 42, 51-59] and nearly one half of these suggest that US/USE can achieve both excellent sensitivity and negative predictive values (NPV) for malignancy (92-100\%), surpassing conventional US [42, 52-56] (Table 1). One study of 498 nodules reported $97 \%$ sensitivity and $97 \%$ NPV for combined US/

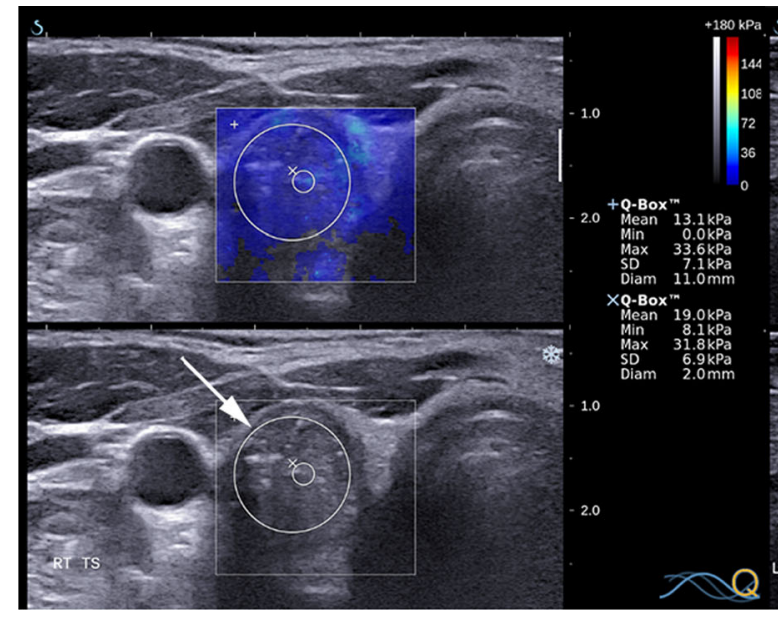

Fig. 14 Transverse and longitudinal SWE with B mode US images of a papillary carcinoma (left) and a hyperplastic nodule (right) respectively. The SWE elastogram chromatic scale ranges from blue to red, denoting soft to stiff $(0 \mathrm{kPa}$ to $180 \mathrm{kPa})$. The cancer appears uniformly soft with a maximum

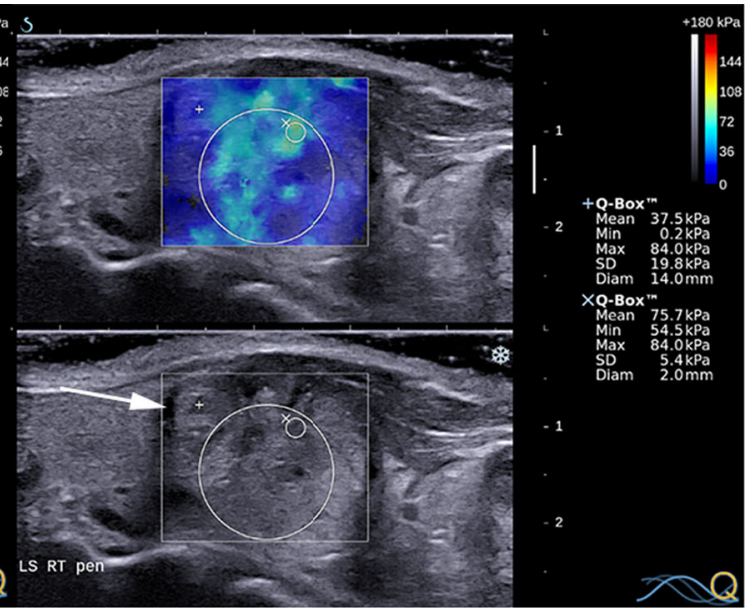

SWE stiffness of $33.6 \mathrm{kPa}$ whereas the hyperplastic nodule appears heterogeneously stiff with a maximum SWE stiffness of $84.0 \mathrm{kPa}$. These would be false negative and false positive for malignancy respectively using any recently published SWE cutoff (cutoffs range between 39.3-66 kPa) 
Table 1 Diagnostic performances of conventional US and a combination of conventional US and USE for diagnosing thyroid malignancy

\begin{tabular}{|c|c|c|c|c|c|c|c|c|c|c|c|c|}
\hline \multirow[t]{2}{*}{ First author, year (citation) } & \multirow[t]{2}{*}{$\mathrm{n}(\%$ malignant $)$} & \multirow[t]{2}{*}{ Type } & \multicolumn{2}{|c|}{ Sensitivity (\%) } & \multicolumn{2}{|c|}{ Specificity (\%) } & \multicolumn{2}{|c|}{ Accuracy $(\%)$} & \multicolumn{2}{|c|}{ PPV (\%) } & \multicolumn{2}{|c|}{ NPV (\%) } \\
\hline & & & US & US/USE & US & US/USE & US & US/USE & US & US/USE & US & US/USE \\
\hline Sebag, 2010 [46] & $146(19.9)$ & SWE & 51.9 & 81.5 & 97 & 97 & ND & ND & 82.4 & 88 & 88.1 & 95 \\
\hline Trimboli, 2012 [49] & $498(25.3)$ & SE & 85 & 97 & 54 & 34 & 62 & 50 & 38 & 33 & 91 & 97 \\
\hline Ragazzoni, 2012 [52] & $132(30.3)$ & SE & 70 & 85 & 92.4 & 83.7 & 85.6 & 84.1 & 80 & 69.4 & 87.6 & 92.8 \\
\hline Cappelli, 2012 [51] & $159(9.4)$ & SE & 80 & 100 & 75 & 70.8 & 75.4 & 73.6 & 25 & 26.3 & 97.2 & 100 \\
\hline Moon, 2012 [37] & $703(30.8)$ & SE & 91.7 & 92.2 & 66.7 & 65 & 74.4 & 73.4 & 55.1 & 54.1 & 94.7 & 94.9 \\
\hline Unluturk, 2012 [35] & $237(24.5)$ & SE & 69 & 41 & 85 & 93 & 81 & 81 & 60 & 67 & 89 & 83 \\
\hline Veyrieres, 2012 [50] & $297(11.8)$ & SWE & 77.1 & 97.1 & 58 & 55.3 & ND & ND & 19.7 & 22.5 & 95 & 99.3 \\
\hline Shweel, 2013 [48] & $66(24.2)$ & SE & 92 & 95.4 & 72.9 & 94.8 & 60.1 & 95.2 & 95 & 82.3 & 63.1 & 98.8 \\
\hline Russ, 2013 [47] & $991(6.7)$ & SE & 95.7 & 98.5 & 61 & 44.7 & 62 & 48.3 & ND & ND & 99.7 & 99.8 \\
\hline Garino, 2014 [54] & $108(30.6)$ & SE & 61 & 88 & 83 & 77 & 76 & 81 & 61 & 63 & 83 & 94 \\
\hline Liu, 2014 [53] & $331(30.5)$ & SWE & 76.2 & 87.1 & 83 & 73.9 & 81 & 78 & 66.4 & 59.5 & 88.8 & 92.9 \\
\hline
\end{tabular}

Only published studies with both documented sensitivity and NPV results are shown, and those with high sensitivities and NPVs ( $>95 \%)$ are indicated in bold. US conventional US, $P P V$ positive predictive value, $N P V$ negative predictive value, US/USE combined conventional US and USE, SE strain USE, $S W E$ shear wave elastography, $N D$ not documented

USE compared to $85 \%$ sensitivity and $91 \%$ NPV for conventional US alone [54]. This is an important finding as it suggests that clinicians may be able to use USE as an ancillary technique to identify nodules with a very low risk of malignancy, which may be placed under observation rather than undergo invasive investigations including FNAC or surgery. Indeed, another study that evaluated 991 nodules using both strain ratios and conventional US within a standardised classification system (US-TIRADS) also documented high sensitivity (98.5\%) and NPV (99.8 \%) for combined US-TIRADS/ USE and importantly estimated that FNAC could be reduced by $34 \%$ using this combined approach [52]. In this respect, the additional value of USE is likely to be greatest for nodules that are indeterminate on conventional US in terms of displaying one or two mildly suspicious features of malignancy, which would all undergo FNAC under the current guidelines. This probably includes nodules classified as TIRADS 3 "probably benign" and possibly TIRADS 4A "low suspicion of malignancy", which collectively comprise approximately $80 \%$ of FNACs and of which $90 \%$ are ultimately benign [60]. USE is unlikely to be useful in terms of altering the clinical decision of whether to perform FNAC for nodules that are already very suspicious for malignancy or completely benign on conventional US.

Another potential role for USE is for nodules with nondiagnostic or indeterminate cytological results on FNAC (e.g., cellular atypia of indeterminate significance), which affects approximately $30 \%$ of FNACs [61-63]. A substantial proportion of these nodules undergo hemi-thyroidectomy for a definitive diagnosis because repeat FNACs are nondiagnostic or because of limitations in cytological diagnosis of follicular lesions, although $75-80 \%$ of these are ultimately non-neoplastic [61, 62, 64]. Encouragingly several reports indicate that USE or combined US/USE can attain high NPVs for malignancy in this group (95-100 \% NPV) [56, 59, 65, 66], although one study has documented the opposite findings (50\% NPV) [39]. If these positive findings can be validated in larger studies, USE could lower the number of hemithyroidectomies performed in this subgroup.

\section{- Potential limitations of USE}

Unfortunately, follicular carcinomas appear to have low mean USE indices that overlap substantially with benign hyperplastic nodules and follicular adenomas [33]. This is disappointing given the challenges in pre-surgical diagnosis of follicular lesions but unsurprising given their histological similarities [67]. Sparse data also suggest that USE is suboptimal for detecting medullary thyroid carcinomas [68]. Macrocalcifications are a confounding factor for USE as they increase mean stiffness estimates of ROIs that include them and are common in both benign and malignant pathologies $[69,70]$. However, some evidence suggests that novel semiquantitative USE indices such as strain heterogeneity may be diagnostically accurate in partially calcified nodules [70]. Predominantly cystic nodules are unsuitable for strain USE but not SWE for technical reasons related to uneven stress transmission in the former [28, 41]. Graves disease, Hashimoto's thyroiditis and subacute thyroiditis can cause parenchymal stiffening [71-73] and therefore would be expected to lower the accuracy of strain USE for malignancy, although some evidence suggests that strain USE is still accurate for nodules in a background thyroiditis [66, 74]. As SWE does not require a reference tissue, nodule stiffness estimated by SWE is probably not altered significantly by a background thyroiditis $[69$, 75]. The influence of nodule dimensions on USE indices is 


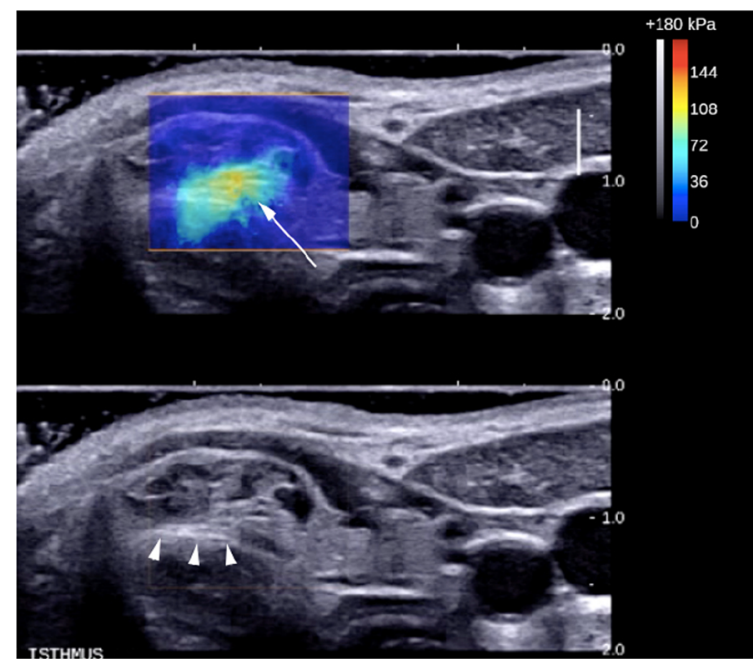

Fig. 15 Transverse SWE with B mode US images of two hyperplastic nodules (left, right) showing elastographic artefacts. The SWE elastogram chromatic scale ranges from blue to red, denoting soft to stiff $(0 \mathrm{kPa}$ to $180 \mathrm{kPa})$. The left image highlights stress concentration artefact in an isthmic nodule (white arrow), which occurs because the nodule produces a convex bulge of the skin and is compressed against the relatively hard trachea despite the use of an ample gel layer on the skin

controversial although USE appears to have similar diagnostic performances for nodules ranging between 1 and $3 \mathrm{~cm}$ in diameter. Some evidence indicates that USE indices and diagnostic accuracies are reduced in infra-centimetric nodules, although many reports have found USE still to be highly accurate in this subgroup $[58,70,76,77]$.

\section{- Practical aspects and operator dependence of USE}

USE is a dynamic technique with fluctuating elastographic appearances due to its intrinsic sensitivity to miniscule displacements that are continually occurring under physiological conditions. Various components of USE acquisition and interpretation are operator dependent including freehand compression for strain USE, selection of imaging planes through nodules, selection of representative elastograms, qualitative scoring of elastograms and placement of ROIs for (semi-)quantitative measurements [78]. Strain USE using freehand compression is highly dependent on an optimal axial compression technique, which is hampered by competing non-axial motions (e.g., arterial pulsations and respiration) and the different mobilities of tissues bordering the thyroid (e.g., immobile trachea and mobile vessels). Carotid artery strain USE and SWE circumvent this source of operator dependence. Nevertheless, irrespective of the USE technology used, the operator influences the amount of resting pressure applied via a motionless transducer, termed precompression, which in turn can alter tissue stiffness [34]. This phenomenon reflects the fact the Young's modulus of biological tissues increases as strain is increased, termed strain hardening, although this effect is

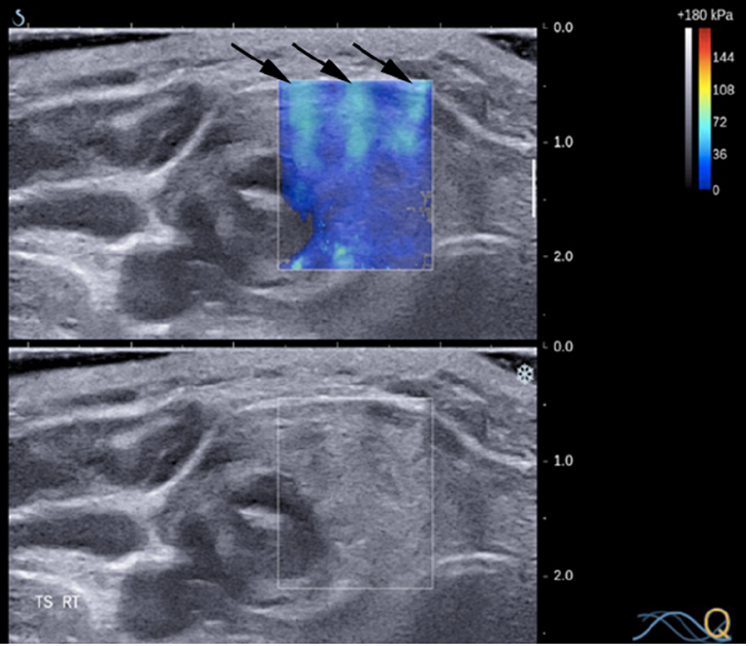

surface. The right image shows vertically aligned bands of light blue colour that traverse several anatomic structures (black arrows). These are suggestive of technology-related push pulse artefacts corresponding to peaks of shear waves induced at different lengths along the transducer. Although they can be excluded from SWE measurements, they may be inadvertently included if subtle

minimal for very small strains $(<10 \%)$. To mitigate this problem, USE should be performed with minimal pressure applied, which may be facilitated by maintaining an ample US gel layer between the transducer and skin.

Various elastographic pitfalls and artefacts can occur in thyroid USE, which need to be recognised and avoided. High stiffness areas due to the stress concentration frequently develop in the near field beneath the transducer including the superficial aspect of some thyroid nodules, as well as at boundaries of tissues with contrasting stiffness including the margins of some nodules. Isthmic nodules are especially prone to stress concentration effects because they tend to produce a focal skin bulge with uneven contact under the flat transducer and be compressed directly against the unyielding trachea. Other artefacts can also develop because of a suboptimal compression technique, competing non-axial motions, presence of cystic fluid and limitations of specific USE technologies (Fig. 15) [25, 79].

\section{- Reproducibility of USE}

Given the aforementioned sources of operator influence, practical challenges and artefacts, establishing a high reproducibility of thyroid USE is an important objective. An early report of strain USE had disappointing reproducibility results [80]; however most recent studies using newer USE technologies report substantial to excellent intra- and inter-observer agreements [49, 55, 57, 79, 81-85]. Evidently, the inclusion of compression quality assurance scales on strain USE systems has had a positive influence on this aspect. Nevertheless, the 
fact remains that (semi-)quantitative USE indices have differed substantially between studies, including those evaluating identical SWE technologies [35]. These discrepancies may reflect sampling variations although their magnitude and pattern raises questions about additional mechanisms, which in turn may influence reproducibility. One postulation is that operators may be performing USE using different degrees of precompression (Fig. 16) and may even be unconsciously influenced by the nodule's greyscale appearances on the split-screen display (cognitive bias) $[86,87]$. At present, precompression cannot be measured or standardised reliably because pressure sensors are not incorporated within transducers.

\section{- Current and future directions of USE}

According to recently published guidelines from the European Federation of Societies of Ultrasound in Medicine and Biology (EFSUMB): "elastography is an additional tool for thyroid lesion differentiation" and "based on expert opinion, elastography may be used to guide follow-up of lesions negative for malignancy at FNAC" [88]. This cautious endorsement reflects the current controversies in thyroid USE evidence. Clearly further research is required including large multi-centre prospective trials of nodules with less pre-selection to evaluate different nodule characteristics, uncommon pathologies and reproducibility and ultimately determine how USE can be integrated with conventional US into emerging malignant risk classification systems (e.g., TIRADS). In this respect, clarifying precisely which types of nodule are unsuitable for thyroid USE will be critical to optimising its accuracy.

Although controversial, USE shows promise as an adjunct to conventional US for reliable identification of benignity in a select group of nodules on the initial US examination as well as those with non-diagnostic or indeterminate cytological results following FNAC. Even if these indications are validated in future studies, several issues will still need to be addressed before USE can be accepted widely in routine practice. USE technologies should be robust and simple to apply by the range of health care professionals who perform thyroid US routinely. The specific strengths and limitations of each USE technology including artefacts need to be catalogued systematically. While it is acknowledged that USE technologies are proprietary and their outputs may not be interchangeable, there should be greater standardisation of thyroid USE, for example by unifying nodule-grading systems and elastogram chromatic scales. Fortunately, USE technologies are continually improving including with respect to measurement precision and quality assurance, which should augment their diagnostic accuracies and reliabilities. Ideally, with advances in CAD software, a nodule's grey scale and elastographic features could be analysed automatically and converted into a single estimate of its malignant risk. There are still some hurdles to overcome although, at the current pace of promising research and technological advances, USE may well become a valuable complementary technique for evaluating thyroid nodules in the near future.

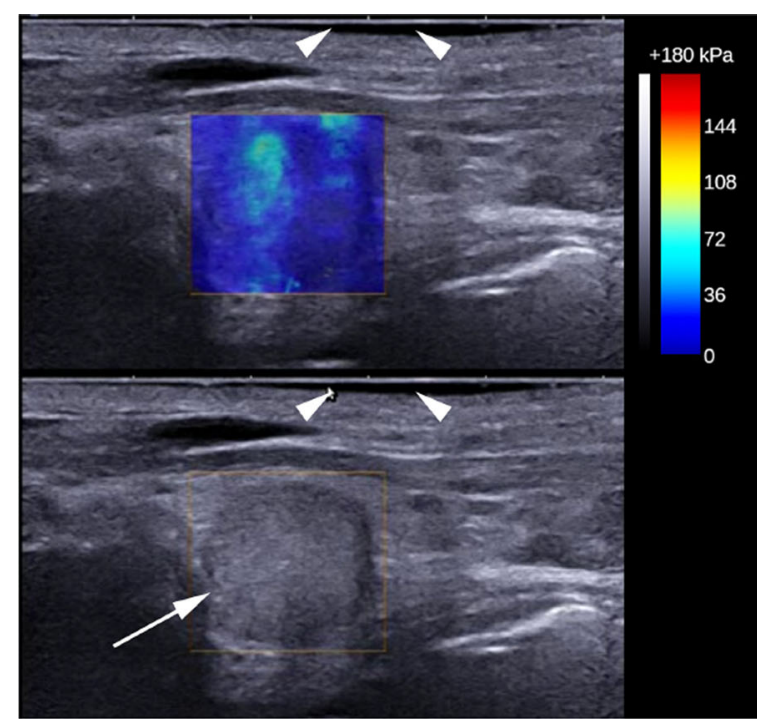

Fig. 16 Longitudinal SWE with a B mode US image of a papillary carcinoma under different degrees of precompression applied by the operator. The SWE elastogram chromatic scale ranges from blue to red, denoting soft to stiff ( $0 \mathrm{kPa}$ to $180 \mathrm{kPa}$ ). The left image was acquired using minimal precompression as evidenced by a preserved gel layer between the skin and transducer (arrowheads), whereas the right image

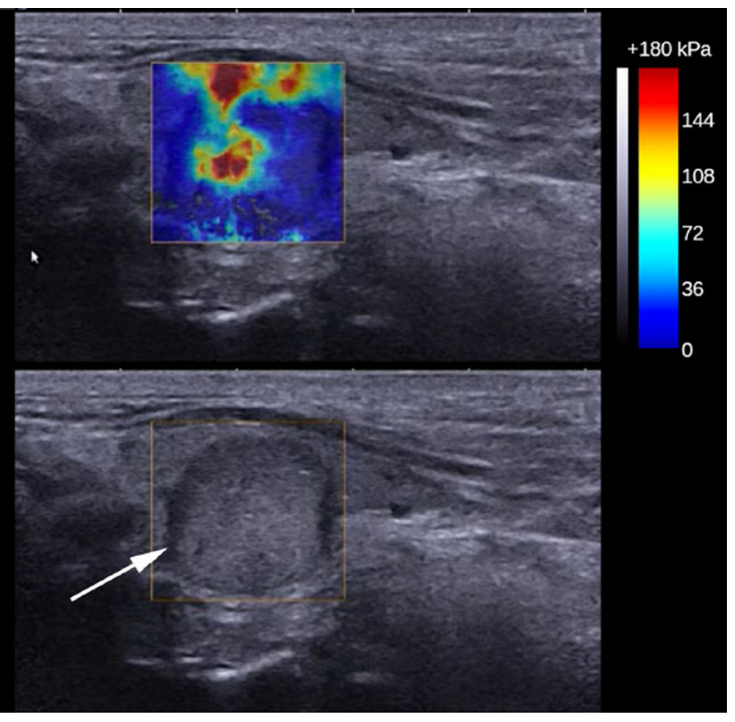

was acquired using mild precompression as evidenced by the fact that the gel interface layer is effaced and the nodule is closer to the skin surface. The SWE stiffness of the cancer is much higher in the right image. This deliberate example illustrates how variations in precompression can bias USE results 


\section{Conclusion}

Innovative advances in high-resolution ultrasound now enable detailed anatomical characterisation and accurate differentiation of benign from malignant disease. Ultrasound has become the core component of thyroid nodule guidelines, but it is important that the key technological aspects of the modality are understood and that challenges and limitations remain with the technique. The large evidence base for ultrasound elastography indicates that the assessment of nodule stiffness can improve the imaging evaluation of thyroid lesions and potentially avoids unnecessary FNAC/surgery for benign nodules, particularly if integrated with US classification. The potential for 3D and CEUS in thyroid nodule US has not yet been realised, but the emergence of these novel approaches is an illustration of the huge strides that have been made in the underlying ultrasound technology.

Acknowledgments Dr Bhatia's contribution was supported by a grant from the Research Grants Council of the Hong Kong Special Administrative Region, China (grant Chinese University of Hong Kong; project no. 460412). The authors wish to thank Dr Simon Elliott (Consultant Radiologist, Freeman Hospital, Newcastle, UK) for reviewing the manuscript and providing specific clinical images and Mr Kevin K.W. Leung (Senior Technician, Radiology Department, Prince of Wales Hospital, Hong Kong) for his assistance with illustrations. Both authors contributed equally to this article. During the writing of this article, technological advice and images were provided by ultrasound system specialists representing a number of UK vendors (Philips, Toshiba, Hitachi and Siemens). The selection of vendors was based on the clinical practice at the authors' institutions only. No financial support was received from any of the manufacturers and the authors have no commercial interest to declare.

Open Access This article is distributed under the terms of the Creative Commons Attribution License which permits any use, distribution, and reproduction in any medium, provided the original author(s) and the source are credited.

\section{References}

1. Perros P, Boelaert K, Colley S, Evans C, Evans RM, Gerrard Ba G (2014) Guidelines for the management of thyroid cancer. Clin Endocrinol (Oxf) 81(Suppl 1):1-122

2. Kim EK, Park CS, Chung WY, Oh KK, Kim DI, Lee JT et al (2002) New sonographic criteria for recommending fine-needle aspiration biopsy of nonpalpable solid nodules of the thyroid. AJR Am J Roentgenol 178:687-691

3. Gibbs V, Cole D, Sassano A (2009) Relationship between spatial pulse length and bandwidth. In: Gibbs V, Cole D, Sassano A (eds) Ultrasound physics and technology: how, why and when, 1 st edn. Churchill Livingstone, Elsevier, p 31

4. Dean CR (2011) Spatial and frequency compounding. In: Allan PL, Baxter GM, Weston MJ (eds) Clinical ultrasound, 3rd edn. Elsevier, Churchill Livingstone, pp 37-38

5. Dean CR (2011) Adaptive processing. In: Allan PL, Baxter GM, Weston MJ (eds) Clinical ultrasound, 3rd edn. Elsevier, Churchill Livingstone, pp 38-40
6. Dean CR (2011) Dynamic range. In: Allan PL, Baxter GM, Weston MJ (eds) Clinical ultrasound, 3rd edn. Churchill Livingstone, Elsevier, Spain, p 36

7. Gibbs V, Cole D, Sassano A (2009) Harmonic imaging. In: Gibbs V, Cole D, Sassano A (eds) Ultrasound physics and technology: how, why and when, 1st edn. Elsevier, Churchill Livingstone, pp 115-116

8. Dominguez JM, Baudrand R, Cerda J, Campusano C, Fardella C, Arteaga E et al (2011) An ultrasound model to discriminate the risk of thyroid carcinoma. Acad Radiol 18:242-245

9. Moon WJ, Baek JH, Jung SL, Kim DW, Kim EK, Kim JY et al (2011) Ultrasonography and the ultrasound-based management of thyroid nodules: consensus statement and recommendations. Korean J Radiol 12:1-14

10. Hambly NM, Gonen M, Gerst SR, Li D, Jia X, Mironov S et al (2011) Implementation of evidence-based guidelines for thyroid nodule biopsy: a model for establishment of practice standards. AJR Am J Roentgenol 196:655-660

11. Davies L, Welch HG (2006) Increasing incidence of thyroid cancer in the United States, 1973-2002. JAMA 295:2164-2167

12. Frates MC, Benson CB, Charboneau JW, Cibas ES, Clark OH, Coleman BG et al (2005) Management of thyroid nodules detected at US: Society of Radiologists in Ultrasound consensus conference statement. Radiology 237:794-800

13. Kwak JY (2013) Indications for fine needle aspiration in thyroid nodules. Endocrinol Metab (Seoul) 28:81-85

14. Moon WJ, Jung SL, Lee JH, Na DG, Baek JH, Lee YH et al (2008) Benign and malignant thyroid nodules: US differentiation-multicenter retrospective study. Radiology 247:762-770

15. Hoang JK, Lee WK, Lee M, Johnson D, Farrell S (2007) US Features of thyroid malignancy: pearls and pitfalls. Radiographics 27:847860, discussion 861-845

16. Cosgrove DO (2011) Shadowing and increased sound transmission. In: Allan PL, Baxter GM, Weston MJ (eds) Clinical ultrasound, 3rd edn. Elsevier, Churchill Livingstone, pp 64-65

17. Machado P, Eisenbrey JR, Cavanaugh B, Forsberg F (2012) New image processing technique for evaluating breast microcalcifications: a comparative study. J Ultrasound Med 31:885-893

18. Ciledag N, Arda K, Aribas BK, Aktas E, Kose SK (2012) The utility of ultrasound elastography and MicroPure imaging in the differentiation of benign and malignant thyroid nodules. AJR Am J Roentgenol 198:W244-W249

19. Slapa RZ, Jakubowski WS, Slowinska-Srzednicka J, Szopinski KT (2011) Advantages and disadvantages of 3D ultrasound of thyroid nodules including thin slice volume rendering. Thyroid Res 4:1

20. Acharya UR, Vinitha Sree S, Krishnan MM, Molinari F, Garberoglio R, Suri JS (2012) Non-invasive automated 3D thyroid lesion classification in ultrasound: a class of ThyroScan systems. Ultrasonics 52: $508-520$

21. Jang M, Kim SM, Lyou CY, Choi BS, Choi SI, Kim JH (2012) Differentiating benign from malignant thyroid nodules: comparison of 2- and 3-dimensional sonography. J Ultrasound Med 31:197-204

22. Kwak JY, Han KH, Yoon JH, Moon HJ, Son EJ, Park SH et al (2011) Thyroid imaging reporting and data system for US features of nodules: a step in establishing better stratification of cancer risk. Radiology 260:892-899

23. Zhang B, Jiang YX, Liu JB, Yang M, Dai Q, Zhu QL et al (2010) Utility of contrast-enhanced ultrasound for evaluation of thyroid nodules. Thyroid 20:51-57

24. Nemec U, Nemec SF, Novotny C, Weber M, Czerny C, Krestan CR (2012) Quantitative evaluation of contrast-enhanced ultrasound after intravenous administration of a microbubble contrast agent for differentiation of benign and malignant thyroid nodules: assessment of diagnostic accuracy. Eur Radiol 22:1357-1365

25. Bamber J, Cosgrove D, Dietrich CF, Fromageau J, Bojunga J, Calliada $\mathrm{F}$ et al (2013) EFSUMB guidelines and recommendations 
on the clinical use of ultrasound elastography. Part 1: Basic principles and technology. Europ J Ultrasound 34:169-184

26. Hoskins PR (2012) Principles of US elastography. Ultrasound 20:815

27. Asteria C, Giovanardi A, Pizzocaro A, Cozzaglio L, Morabito A, Somalvico F et al (2008) US-elastography in the differential diagnosis of benign and malignant thyroid nodules. Thyroid 18:523-531

28. Rago T, Santini F, Scutari M, Pinchera A, Vitti P (2007) Elastography: new developments in ultrasound for predicting malignancy in thyroid nodules. J Clin Endocrinol Metab 92:2917-2922

29. Bojunga J, Herrmann E, Meyer G, Weber S, Zeuzem S, FriedrichRust M (2010) Real-time elastography for the differentiation of benign and malignant thyroid nodules: a meta-analysis. Thyroid 20 : $1145-1150$

30. Ghajarzadeh M, Sodagari F, Shakiba M (2014) Diagnostic accuracy of sonoelastography in detecting malignant thyroid nodules: a systematic review and meta-analysis. Am J Roentgenol 202:W379W389

31. Lin P, Chen M, Liu B, Wang S, Li X (2014) Diagnostic performance of shear wave elastography in the identification of malignant thyroid nodules: a meta-analysis. Eur Radiol 24:2729-2738

32. Razavi SA, Hadduck TA, Sadigh G, Dwamena BA (2013) Comparative effectiveness of elastographic and B-mode ultrasound criteria for diagnostic discrimination of thyroid nodules: a meta-analysis. Am J Roentgenol 200:1317-1326

33. Sun J, Cai J, Wang X (2014) Real-time ultrasound elastography for differentiation of benign and malignant thyroid nodules: a meta-analysis. J Ultrasound Med 33:495-502

34. Veer V, Puttagunta S (2014) The role of elastography in evaluating thyroid nodules: a literature review and meta-analysis. Eur Arch Otorhinolaryngol. doi:10.1007/s00405-014-3155-7

35. Zhang B, Ma X, Wu N, Liu L, Liu X, Zhang J et al (2013) Shear wave elastography for differentiation of benign and malignant thyroid nodules: a meta-analysis. J Ultrasound Med 32:2163-2169

36. Isarangkul W (1993) Dense fibrosis. another diagnostic criterion for papillary thyroid carcinoma. Arch Pathol Lab Med 117:645-646

37. Gu J, Du L, Bai M, Chen H, Jia X (2012) Preliminary study on the diagnostic value of acoustic radiation force impulse technology for differentiating between benign and malignant thyroid nodules. J Ultrasound Med 31:763-771

38. Kagoya R, Monobe H, Tojima H (2010) Utility of elastography for differential diagnosis of benign and malignant thyroid nodules. Otolaryngol Head Neck Surg 143:230-234

39. Lippolis PV, Tognini S, Materazzi G, Polini A, Mancini R, Ambrosini CE et al (2011) Is elastography actually useful in the presurgical selection of thyroid nodules with indeterminate cytology? J Clin Endocrinol Metab 96:E1826-E1830

40. Unluturk U, Erdogan MF, Demir O, Gullu S, Baskal N (2012) Ultrasound elastography is not superior to grayscale ultrasound in predicting malignancy in thyroid nodules. Thyroid. doi:10.1089/ thy. 2011.0502

41. Bhatia KS, Rasalkar DP, Lee YP, Wong KT, King AD, Yuen HY et al (2011) Cystic change in thyroid nodules: a confounding factor for real-time qualitative thyroid ultrasound elastography. Clin Radiol 66: 799-807

42. Moon HJ, Sung JM, Kim EK, Yoon JH, Youk JH, Kwak JY (2012) Diagnostic performance of gray-scale US and elastography in solid thyroid nodules. Radiology 262:1002-1013

43. Giusti M, Orlandi D, Melle G, Massa B, Silvestri E, Minuto F et al (2013) Is there a real diagnostic impact of elastosonography and contrast-enhanced ultrasonography in the management of thyroid nodules? J Zhejiang University SCIENCE B 14:195-206

44. Wang H, Brylka D, Sun L-N, Lin Y-Q, Sui G-Q, Gao J (2013) Comparison of strain ratio with elastography score system in differentiating malignant from benign thyroid nodules. J Clin Imag 37:50-55
45. Lyshchik A, Higashi T, Asato R, Tanaka S, Ito J, Mai JJ et al (2005) Thyroid gland tumor diagnosis at US elastography. Radiology 237: 202-211

46. Ning C-P, Jiang S-Q, Zhang T, L-t S, Liu Y-J, Tian J-W (2011) The value of strain ratio in differential diagnosis of thyroid solid nodules. Eur J Radiol. doi:10.1016/j.ejrad.2010.12.010:1-6

47. Xing P, Wu L, Zhang C, Li S, Liu C, Wu C (2011) Differentiation of benign from malignant thyroid lesions: calculation of the strain ratio on thyroid sonoelastography. J Ultrasound Med 30:663-669

48. Wang H, Zhao L, Xin X, Wei X, Zhang S, Li Y et al (2014) Diagnostic value of elastosonography for thyroid microcarcinoma. Ultrasonics 54:1945-1949

49. Cantisani V, Grazhdani H, Ricci P, Mortele K, Di Segni M, D’Andrea V et al (2014) Q-elastosonography of solid thyroid nodules: assessment of diagnostic efficacy and interobserver variability in a large patient cohort. Eur Radiol 24:143-150

50. Bhatia KS, Tong CS, Cho CC, Yuen EH, Lee YY, Ahuja AT (2012) Shear wave elastography of thyroid nodules in routine clinical practice: preliminary observations and utility for detecting malignancy. Eur Radiol 22:2397-2406

51. Sebag F, Vaillant-Lombard J, Berbis J, Griset V, Henry JF, Petit P et al (2010) Shear wave elastography: a new ultrasound imaging mode for the differential diagnosis of benign and malignant thyroid nodules. $\mathrm{J}$ Clin Endocrinol Metab 95:5281-5288

52. Russ G, Royer B, Bigorgne C, Rouxel A, Bienvenu-Perrard M, Leenhardt L (2013) Prospective evaluation of thyroid imaging reporting and data system on 4550 nodules with and without elastography. Eur J Endocrinol 168:649-655

53. Shweel M, Mansour E (2013) Diagnostic performance of combined elastosonography scoring and high-resolution ultrasonography for the differentiation of benign and malignant thyroid nodules. Eur $\mathrm{J}$ Radiol 82:995-1001

54. Trimboli P, Guglielmi R, Monti S, Misischi I, Graziano F, Nasrollah $\mathrm{N}$ et al (2012) Ultrasound sensitivity for thyroid malignancy is increased by real-time elastography: a prospective multicenter study. J Clin Endocrinol Metab 97:4524-4530

55. Veyrieres J-B, Albarel F, Lombard JV, Berbis J, Sebag F, Oliver C et al (2012) A threshold value in shear wave elastography to rule out malignant thyroid nodules: a reality? Eur J Radiol 81:3965-3972

56. Cappelli C, Pirola I, Gandossi E, Agosti B, Cimino E, Casella C et al (2012) Real-time elastography: a useful tool for predicting malignancy in thyroid nodules with nondiagnostic cytologic findings. J Ultrasound Med 31:1777-1782

57. Ragazzoni F, Deandrea M, Mormile A, Ramunni MJ, Garino F, Magliona $\mathrm{G}$ et al (2012) High diagnostic accuracy and interobserver reliability of real-time elastography in the evaluation of thyroid nodules. Ultrasound Med Biol 38:1154-1162

58. Liu B, Liang J, Zheng Y, Xie X, Huang G, Zhou L et al (2014) Twodimensional shear wave elastography as promising diagnostic tool for predicting malignant thyroid nodules: a prospective singlecentre experience. Eur Radiol. doi:10.1007/s00330-014-3455-8

59. Garino F, Deandrea M, Motta M, Mormile A, Ragazzoni F, Palestini $\mathrm{N}$ et al (2014) Diagnostic performance of elastography in cytologically indeterminate thyroid nodules. Endocrine. doi:10.1007/s12020014-0438-0

60. Moifo B, Takoeta EO, Tambe J, Blanc F (2014) Reliability of thyroid imaging reporting and data system (TIRADS) classification in differentiating benign from malignant thyroid nodules. Tumour Biol 35: 6769-6776

61. Alexander EK (2008) Approach to the patient with a cytologically indeterminate thyroid nodule. J Clin Endocrinol Metab 93:41754182

62. Yoon JH, Kwak JY, Kim EK, Moon HJ, Kim MJ, Kim JY et al (2010) How to approach thyroid nodules with indeterminate cytology. Ann Surg Oncol 17:2147-2155 
63. Yoon JH, Moon HJ, Kim EK, Kwak JY (2011) Inadequate cytology in thyroid nodules: should we repeat aspiration or follow-up? Ann Surg Oncol 18:1282-1289

64. Rago T, Di Coscio G, Basolo F, Scutari M, Elisei R, Berti P et al (2007) Combined clinical, thyroid ultrasound and cytological features help to predict thyroid malignancy in follicular and Hupsilonrthle cell thyroid lesions: results from a series of 505 consecutive patients. Clin Endocrinol (Oxf) 66:13-20

65. Rago T, Scutari M, Santini F, Loiacono V, Piaggi P, Di Coscio G et al (2010) Real-time elastosonography: useful tool for refining the presurgical diagnosis in thyroid nodules with indeterminate or nondiagnostic cytology. J Clin Endocrinol Metab 95:5274-5280

66. Cantisani V, Ulisse S, Guaitoli E, De Vito C, Caruso R, Mocini R et al (2012) Q-elastography in the presurgical diagnosis of thyroid nodules with indeterminate cytology. PLoS One 7:e50725

67. DeLellis RA, Guiter G, Weinstein BJ (2001) Pathology of the thyroid and parathyroid glands. In: Gnepp DR (ed) Diagnostic and surgical pathology of the head and neck, edn. WB Saunders Company, Philadelphia, pp 431-504

68. Andrioli M, Persani L (2014) Elastographic techniques of thyroid gland: current status. Endocrine 46:455-461

69. Szczepanek-Parulska E, Woliński K, Stangierski A, Gurgul E, Ruchała M (2014) Biochemical and ultrasonographic parameters influencing thyroid nodules elasticity. Endocrine 47:519-527

70. Kim M-H, Luo S, Ko S-H, Jung SL, Lim D-J, Kim Y (2014) Elastography can effectively decrease the number of fine-needle aspiration biopsies in patients with calcified thyroid nodules. Ultrasound Med Biol 40:2329-2335

71. Sporea I, Vlad M, Bota S, Sirli RL, Popescu A, Danila M et al (2011) Thyroid stiffness assessment by acoustic radiation force impulse elastography (ARFI). Ultraschall Med 32:281-285

72. Ruchala M, Szczepanek-Parulska E, Zybek A, Moczko J, Czarnywojtek A, Kaminski G et al (2012) The role of sonoelastography in acute, subacute and chronic thyroiditis: a novel application of the method. Eur J Endocrinol 166:425-432

73. Kim I, Kim E, Yoon J, Han K, Son E, Moon H et al (2014) Erratum to "diagnostic role of conventional ultrasonography and Shearwave elastography in asymptomatic patients with diffuse thyroid disease: initial experience with 57 patients" by Kim I, et al. (Yonsei Med J 2014;55:247-53.). Yonsei Med J 55:548

74. Şahin M, Çakal E, Özbek M, Güngünes A, Arslan MS, Akkaymak ET et al (2014) Elastography in the differential diagnosis of thyroid nodules in Hashimoto thyroiditis. Med Oncol 31:97

75. Magri F, Chytiris S, Capelli V, Alessi S, Nalon E, Rotondi M et al (2012) Shear wave elastography in the diagnosis of thyroid nodules: feasibility in the case of coexistent chronic autoimmune Hashimoto's thyroiditis. Clin Endocrinol (Oxf) 76:137-141
76. Dighe M, Luo S, Cuevas C, Kim Y (2013) Efficacy of thyroid ultrasound elastography in differential diagnosis of small thyroid nodules. Eur J Radiol 82:e274-e280

77. Wang Y, Dan HJ, Dan HY, Li T, Hu B (2010) Differential diagnosis of small single solid thyroid nodules using real-time ultrasound elastography. J Int Med Res 38:466-472

78. Ko SY, Kim E-K, Sung JM, Moon HJ, Kwak JY (2014) Diagnostic performance of ultrasound and ultrasound elastography with respect to physician experience. Ultrasound Med Biol 40:854-863

79. Bhatia K, Tong CS, Cho CC, Yuen EH, Lee J, Ahuja AT (2012) Reliability of shear wave ultrasound elastography for neck lesions identified in routine clinical practice. Europ J Ultrasound 33:463-468

80. Park SH, Kim SJ, Kim E-K, Kim MJ, Son EJ, Kwak JY (2009) Interobserver agreement in assessing the sonographic and elastographic features of malignant thyroid nodules. Am J Roentgenol 193:W416-W423

81. Merino S, Arrazola J, Cardenas A, Mendoza M, De Miguel P, Fernandez $\mathrm{C}$ et al (2011) Utility and interobserver agreement of ultrasound elastography in the detection of malignant thyroid nodules in clinical care. Am J Neuroradiol 32:2142-2148

82. Kim JK, Baek JH, Lee JH, Kim JL, Ha EJ, Kim TY et al (2012) Ultrasound elastography for thyroid nodules: a reliable study? Ultrasound Med Biol 38:1508-1513

83. Zhang Y-F, Xu H-X, He Y, Liu C, Guo L-H, Liu L-N et al (2012) Virtual touch tissue quantification of acoustic radiation force impulse: a new ultrasound elastic imaging in the diagnosis of thyroid nodules. PLoS One 7:e49094

84. Lim D-J, Luo S, Kim M-H, Ko S-H, Kim Y (2012) Interobserver agreement and intraobserver reproducibility in thyroid ultrasound elastography. Am J Roentgenol 198:896-901

85. Calvete AC, Rodríguez JM, de Dios B-MJ, Ríos A, Abellán-Rivero D, Reus M (2013) Interobserver agreement for thyroid elastography: value of the quality factor. J Ultrasound Med 32:495-504

86. Barr RG, Zhang Z (2012) Effects of precompression on elasticity imaging of the breast: development of a clinically useful semiquantitative method of precompression assessment. J Ultrasound Med 31: 895-902

87. Bhatia K, Lam ACL, King AD, Ahuja AT (2014) Influences of variations in resting pressure applied by a transducer on Ultrasound shear wave elastography in the thyroid. European Congress of Radiology. Available via http://posterng.netkey.at/esr/viewing/ index.php? module=viewing poster\&pi=121416. Accessed Nov 2014

88. Cosgrove D, Piscaglia F, Bamber J, Bojunga J, Correas JM, Gilja O et al (2013) EFSUMB guidelines and recommendations on the clinical use of ultrasound elastography. part 2: clinical applications. Europ J Ultrasound 34:238-253 